\title{
SEROTONIN RECEPTORS: SUBTYPES, FUNCTIONAL RESPONSES AND THERAPEUTIC RELEVANCE
}

\author{
PRAMOD R. SAXENA \\ Department of Pharmacology, Dutch Migraine Research Group and Cardiovascular \\ Research Institute ("COEUR"), Faculty of Medicine and Health Sciences, \\ Erasmus University Rotterdam, Post Box 1738, 3000 DR Rotterdam, The Netherlands
}

\begin{abstract}
Recent, rapid progress in the molecular biology of serotonin (5-HT) receptors requires conceptual re-thinking with respect to receptor classification. Thus, based on operational criteria (agonist and antagonist rank order), as well as transduction mechanisms involved and the structure of the receptor protein, the Nomenclature Committee of the Serotonin $C l u b$ has proposed the following classification and nomenclature: the main receptor types $5-\mathrm{HT}_{1}$ to $5-\mathrm{HT}_{4}$, recombinant receptors (e.g. 5-ht to $_{5}$ - $\mathrm{ht}_{7}$ ) and 'orphan' receptors. The aim of the present review is to discuss the events leading to this classification, the criteria for and functional responses mediated by various 5 -HT receptors, as well as the therapeutic possibilities with $5-\mathrm{HT}$ ligands.
\end{abstract}

Keywords-Anxiety, cardiac disorders, central nervous system diseases, depression, gastric motility disorders, 5-hydroxytryptamine, 5-hydroxytryptamine receptors, hypertension, migraine, pain, serotonin, vomiting.

\section{CONTENTS}

1. Introduction 340

2. Earlier Serotonin Receptor Classifications $\quad 340$

2.1. Gaddum's ' $M$ ' and ' $D$ ' serotonin receptors $\quad 340$

2.2. Non-' $M$ ' and non-' $D$ ' serotonin receptors 341

2.3. 5-HT 1 and 5-HT 'receptors' 341

3. Modern Serotonin Receptor Classification 342

3.1. Development of a framework 342

3.2. Cloning of serotonin receptors $\quad 343$

3.3. Approach to receptor classification 343

3.4. The present classification of serotonin receptors 343

4. Responses Mediated by Serotonin Receptors 350

5. Therapeutic Uses of Serotonin Receptor Ligands 350

$\begin{array}{ll}\text { 5.1. Anxiety states } & 350\end{array}$

5.2. Other central nervous system diseases

5.3. Migraine 355

5.4. Vomiting 356

5.5. Hypertension 356

5.6. Gastric motility disorders 356

5.7. Pain 35 ?

5.8. Cardiac disorders 357

6. Closing Remarks 357

$\begin{array}{ll}\text { References } & 358\end{array}$ 


\section{INTRODUCTION}

Serotonin (5-hydroxytryptamine; 5-HT) is a neurotransmitter in the CNS, but is also present in particularly high concentrations in blood platelets and the enterochromaffin cells of gastrointestinal mucosa. Though the vasoconstrictor properties of defibrinated blood and blood serum were long known (Ludwig and Schmidt, 1868), it was only in 1948 that Page (1958) succeeded in isolating a crystalline complex 'serotonin' from the blood serum (Rapport et al., 1948); the active moiety of this complex was found to be 5-HT (Rapport, 1949). In the 1930s, Erspamer and colleagues became involved in the characterization of 'enteramine' from the enterochromaffin cells in the gastrointestinal tract (see Erspamer, 1954). Subsequently, 'enteramine' was also identified as 5-HT and the chemical identity of the natural and synthetic serotonin was backed by the similarity of pharmacological profile, such as contraction of the sheep carotid artery, guinea-pig, mouse and rabbit jejunum, rat and cat uterus and cat nictitating membrane, triphasic blood pressure response and antagonism by yohimbine and potentiation by cocaine of the sheep carotid artery contraction (Erspamer, 1954; Page, 1958). Thus, the scene was set for the characterization of serotonin receptors.

\section{EARLY SEROTONIN RECEPTOR CLASSIFICATIONS}

\subsection{Gaddum's ' $M$ ' and ' $D$ ' Serotonin Receptors}

Woolley and Shaw (1953a,b) and Page and McCubbin (1953) reported that the vascular responses to serotonin could be antagonized by several drugs including some tryptamine derivatives. Gaddum (1953) found that the guinea-pig isolated ileum was selectively desensitized to serotonin or substance $\mathbf{P}$ by high concentrations of these substances, suggesting that the two compounds activated different receptor populations. The serotonin-induced contraction of the guinea-pig ileum was not affected by drugs such as diphenhydramine, nicotine (high doses), hexamethonium or decamethonium, but was partially suppressed by atropine and cocaine, as well as by its own repeated administration, at which time the responses to histamine, acetylcholine, pilocarpine or nicotine were unaffected (Feldberg and Toh, 1953; Rapport and Koelle, 1953; Rocha e Silva et al., 1953). Gaddum and Hameed (1954) postulated that there must be two types of receptors on the enteric parasympathetic ganglia, which responded to either serotonin or nicotine. It was also reported that the vasoconstrictor effect of serotonin on the rabbit ear artery was not much affected by piperoxan, atropine or cocaine, was moderately antagonized by dibenamine and gramine, but was potently blocked by lysergide, dihydroergotamine or ergotamine.

A vital step towards characterization of serotonin receptors was undertaken by Gaddum and Picarelli (1957), who reported that the scrotonin-induced guinea-pig ileum contraction was only partially blocked by either morphine or dibenzyline (phenoxybenzamine), but was completely antagonized by the combined use of the two compounds. Furthermore, lysergide, 2-bromolysergide and dihydroergotamine completely antagonized the response to serotonin in the morphine-treated ileum, and the same was true for atropine and cocaine in the dibenzyline-treated ileum. It was concluded, therefore, that serotonin activated two different types of receptors: an ' $\mathrm{M}$ ' serotonin receptor, located on the parasympathetic ganglion and mediating acetylcholine release from postganglionic nerve endings, and a ' $D$ ' serotonin receptor, located on smooth muscles and directly contracting the muscle (Fig. 1). However, it may be noted that the interference of the contractile effect of serotonin by morphine and atropine was due to the inhibition of acetylcholine rclease (sec Saxena, 1970) and its interaction with the muscarinic receptor, respectively; only cocaine proved to be a weak ' $M$ ' serotonin receptor antagonist (see Fozard, 1990), while phenoxybenzamine acted as an unspecific antagonist.

For a long time, no potent and selective antagonist at ' $M$ ' serotonin receptors was reported, but a number of compounds (e.g. cyproheptadine, lysergide, methysergide, pizotifen, mianserin) became known as ' $D$ ' serotonin receptor antagonists. 


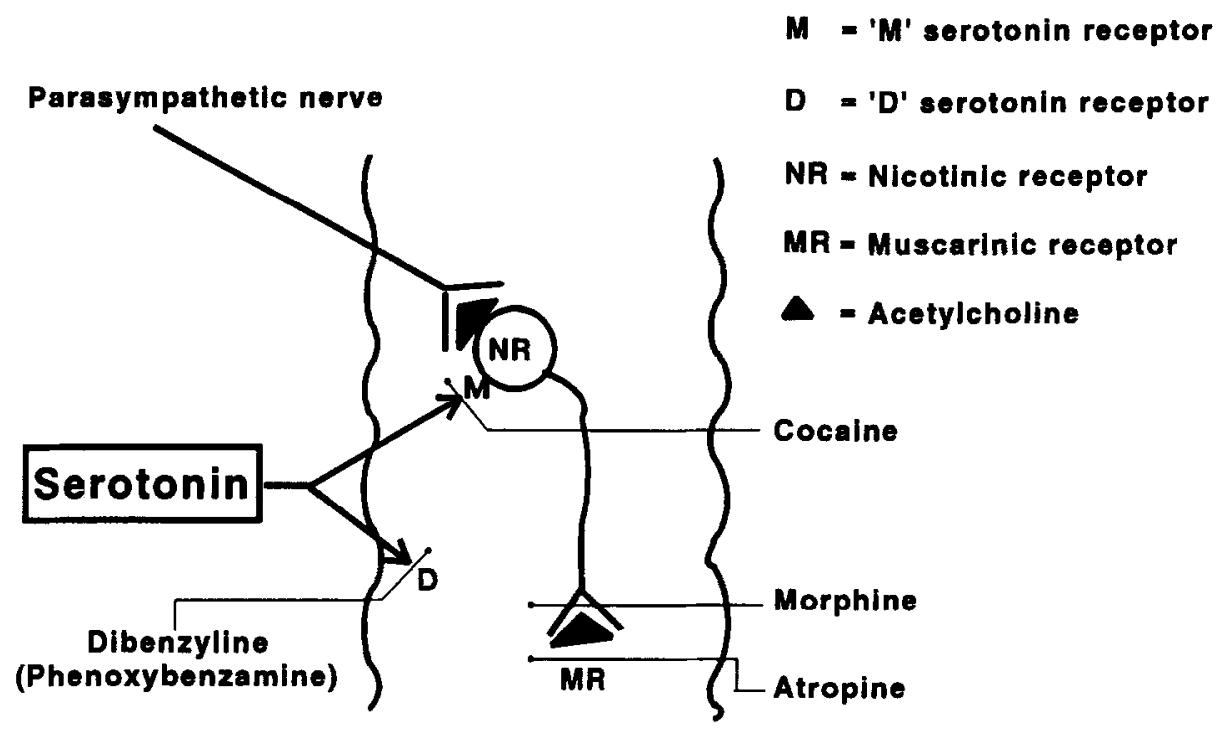

Guinea-pig ileum

Fig. 1. Graphic illustration of the location of ' $M$ ' and ' $D$ ' serotonin receptors in the guinea-pig ileum.

\subsection{Non-'M' and Non-'D' Serotonin Receptors}

Despite the ' $M$ ' and ' $D$ ' serotonin receptor classification becoming widely accepted, there were some responses to serotonin which could not be placed within this scheme. For example, in the carly 1970 s, it was reported that the ' $D$ ' receptor antagonists, mianserin and cyproheptadine, failed to antagonize the vasoconstrictor effect of serotonin in the canine external carotid arterial bed (Fig. 2). Therefore, it was concluded that the serotonin receptors in the external carotid vascular bed of the dog were of a 'special' type and could not be categorized as either ' $M$ ' or ' $D$ ' type (Saxena et al., 1971; Saxena, 1972; Saxena and De Vlaam-Schluter, 1974).

\subsection{5-HT, and 5-HT $\mathbf{T}_{\mathbf{2}}$ 'Receptors'}

Bennett and Aghajanian (1974) reported the first successful radioligand binding study of serotonin receptors using $\mathrm{D}-\left[{ }^{3} \mathrm{H}\right]$ lysergide. $\left[{ }^{3} \mathrm{H}\right]$ serotonin also showed a high affinity, but because of discrepancies between the binding of $\left[{ }^{3} \mathrm{H}\right]$ lysergide and $\left[{ }^{3} \mathrm{H}\right]$ serotonin, a recognition site with two different states was suggested (Bennett and Snyder, 1976; Fillion et al., 1978). However, further studies with $\left[{ }^{3} \mathrm{H}\right]$ serotonin, $\left[{ }^{3} \mathrm{H}\right]$ spiperone and $\left[{ }^{3} \mathrm{H}\right] l y s e r g i d e$ enabled Peroutka and Snyder (1979) to suggest the existence of two distinct serotonin 'receptors'-a 5-HT 'receptor' (high nanomolar affinity for serotonin) and a 5- $\mathrm{HT}_{2}$ 'receptor' (high affinity for spiperone and low micromolar affinity for serotonin). Subsequently, Pedigo et al. (1981) reported that the 5-HT binding site could be subdivided into $5-\mathrm{HT}_{1 \mathrm{~A}}$ and $5-\mathrm{HT}_{1 \mathrm{~B}}$ subtypes on the basis of high and low affinity, respectively, for spiperone. Soon, 8-OH-DPAT was recognized as a selective ligand for the 5-HT $\mathrm{HA}_{1 \mathrm{~A}}$ subtype (Middlemiss and Fozard, 1983). This subdivision of the 5-HT continued into 5-HT $\mathrm{HC}_{\mathrm{IC}}$ (Pazos et al., 1984), 5-HT $\mathrm{ID}$ (Heuring and Peroutka, 1987), 5- $\mathrm{HT}_{\mathrm{IE}}$

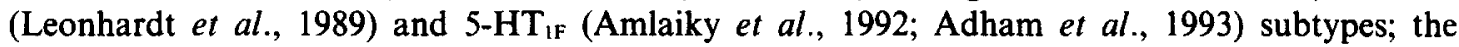
$5-\mathrm{HT}_{1 \mathrm{D}}$ subtype itself also appeared to be heterogeneous (Sumner and Humphrey, 1989). 


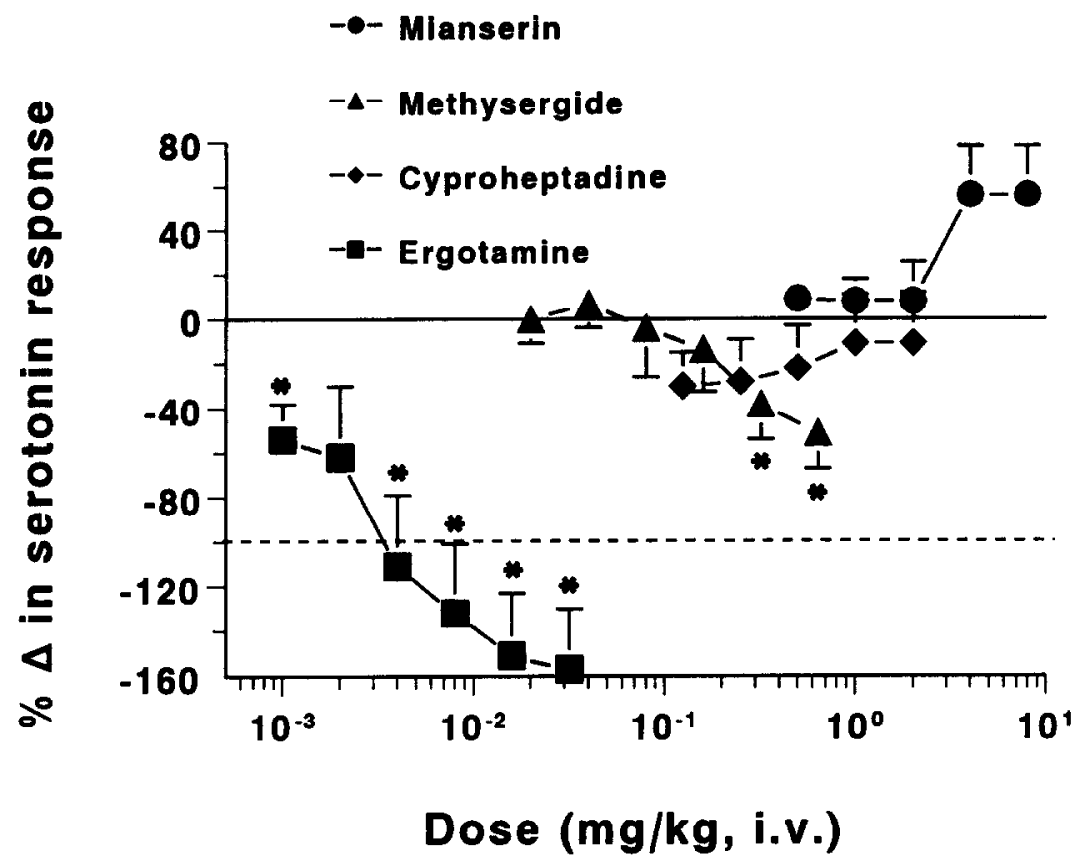

Fig. 2. Dog external carotid artery vascular bed. Effect of mianserin, methysergide, cyproheptadine and ergotamine on the vasoconstrictor response to serotonin. Values below the interrupted line (i.e. change more than $100 \%$ ) mean that serotonin caused vasodilatation instead of vasoconstriction. Note that the apparent reversal of the response to serotonin by ergotamine may have been due to its strong vasoconstrictor property. *Significant $(p<0.05)$ change compared with parallel administration of saline. Data from Saxena et al. (1971) and Saxena (1972).

\section{MODERN SEROTONIN RECEPTOR CLASSIFICATION}

\subsection{Development of a Framework}

The need for a uniform terminology for serotonin receptors was apparent, since these receptors were being referred to by various names ('D', 'M', 5-HT, $5-\mathrm{HT}_{2}, \mathrm{~S}_{1}, \mathrm{~S}_{2}$ etc.) (Humphrey, 1983; Verdouw et al., 1984). Indeed, it was suggested that the old serotonin receptor classifications "should give way to a new classification based on a $5-\mathrm{HT}_{1}, 5-\mathrm{HT}_{2}, 5-\mathrm{HT}_{n}$ series. . the $5-\mathrm{HT}$ receptors subserving arteriolar dilatation, presynaptic inhibition of sympathetic transmission, autoinhibition in the brain and possibly constriction of arteriovenous anastomoses, could be termed $5-\mathrm{HT}_{1}$. The receptors mediating vaso- and broncho-constriction and platelet aggregation could be called 5- $\mathrm{HT}_{2}$ receptors and those mediating ganglionic stimulation, the Bezold-Jarisch reflex and catecholamine release in the heart should be designated as $5-\mathrm{HT}_{3}$ receptors in place of ' $\mathrm{M}$ ' receptors. As there are many effects of 5-HT which await classification. . . this series could, if needed, be extended by using both numbers and letters (as additional subscripts)" (Verdouw et al., 1984).

In 1986, a group of scientists formulated criteria for the characterization, and a general framework for the nomenclature of scrotonin receptors. From the beginning, it was obvious that either of the two previous classifications proposed by Gaddum and Picarelli (1957) and Peroutka and Snyder (1979) were incomplete, but did complement each other. Therefore, it was decided to build upon these two classifications, taking into account rank order and ligand binding affinities of the agonists and antagonists, with some consideration of the second messenger systems involved. Thus, serotonin receptors werc classified into three main categories: 5-HT, and 5- $\mathrm{HT}_{1}$ binding sites), 5- $\mathrm{HT}_{2}$ (corresponding to most ' $\mathrm{D}$ ' receptors and 5-HT $\mathrm{H}_{2}$ binding sites) and 5- $\mathrm{HT}_{3}$ (equivalent to ' $\mathrm{M}$ ' receptors) (Bradley et al., 1986). The important criteria for classification were: 5-HT, -like receptors-5-carboxamidotryptamine, generally a more potent agonist than serotonin, high affinity for the antagonist methiothepin, but not for ketanserin or ICS 205-930 (tropisetron); 5- $\mathrm{HT}_{2}$ receptors-high affinity for the agonist $\alpha$-methyl-5-HT and antagonists 
ketanserin and methiothepin, but not for tropisetron, coupling to phosphatidylinositol turnover; and 5- $\mathrm{HT}_{3}$ receptors-high affinity for the agonist 2-methyl-5-HT and antagonist tropisetron, but not for ketanserin or methiothepin, part of cation channels. It was clearly pointed out that the $5-\mathrm{HT}_{1}$-like receptors were heterogeneous and that some serotonin responses, e.g. the tachycardia in the pig (Duncker et al., 1985), still defied classification. Shortly thereafter, 5- $\mathrm{HT}_{3}$ recognition sites were described in the brain (Kilpatrick et al., 1987), and evidence in favour of 5-HT $\mathrm{H}_{4}$ receptors began to emerge (see Saxena, 1986; Bom et al., 1988; Dumuis et al., 1988, 1989).

\subsection{Cloning of Serotonin Receptors}

Since the original scheme of serotonin receptor classification was proposed (Bradley et al., 1986), an enormous amount of new information on the molecular biology of serotonin receptors has become available. Several receptors have now been cloned and expressed in cells, and the amino acid sequence and structure of the receptor protein, as well as the gene involved, have been determined. Furthermore, using second messenger responses in the host cell, agonists' and antagonists' rank order of the recombinant serotonin receptors has been compared with that of the native receptors. This process has led to identification of several serotonin receptor clones (Table 1). In the case of 5- $\mathrm{HT}_{4}$ receptors, the clones have two splice variants: a short form with 387 amino acids (5-ht 4 s) and a long form with 407 amino acids (5-ht 4 L ) (Gerald et al., 1994). Both these forms show similar pharmacology (Adham et al., 1995), but the functional effects have not been established yet.

\subsection{Approach to Receptor Classification}

The knowledge accumulating from molecular biological work compels reconsideration of conceptual thinking behind receptor classification (Hoyer et al., 1994), not only in the case of serotonin, but for other neurotransmitters. The Nomenclature Committee of the Serotonin Club, which evolved the Bradley Classification of serotonin receptors (Bradley et al., 1986), once again assigned itself this task. After a brief report of its deliberations (Humphrey et al., 1993), a detailed version approved by the main IUPHAR Committee for Receptor Nomenclature has been published recently (Hoyer et al., 1994).

The IUPHAR receptor nomenclature committee has advocated a number of criteria for receptor classification (Kenakin et al., 1992), and these have been extended by the Nomenclature Committee of the Serotonin Club (Hoyer et al., 1994). As shown in Table 2, these criteria fall into three categories: operational (selective agonists, selective antagonists and ligand binding affinities), structural (molecular structure of the receptor protein and, thus, the extent of homology) and transductional (intracellular receptor-effector coupling mechanism). Together, these provide a 'finger-print' basis for identifying distinct receptors.

It is undeniably true that the structure of the receptor protein is the mark of true identity of the receptor. However, it is equally important to realize that substantial changes in the amino acid sequence may not affect (e.g. in the case of $5-\mathrm{HT}_{1 \mathrm{D} \alpha}$ and $5-\mathrm{HT}_{\mathrm{ID} \beta}$ receptors), while little alteration may cause vast changes in the operational characteristics of a receptor (e.g. in case of species homologous 5-HT ${ }_{1 B}$ and 5-HT $\mathrm{ID} \beta_{3}$ receptors) (Hartig et al., 1992).

Two other important recommendations have been made by Hoyer et al. (1994). Firstly, in keeping with the earlier suggestion (Kenakin et al., 1992), it has been advised to use lower case letters for

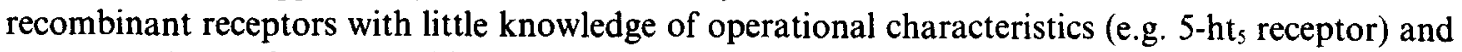
upper case letters for reasonably well-characterized native receptors (e.g. 5- $\mathrm{HT}_{2}$ receptor). Secondly, since not all necessary criteria, as outlined in Table 2, are always available, it is probably not possible to obtain a fully rationale classification scheme. Therefore, it is necessary to hold certain receptors provisionally in an 'orphan' category awaiting further characterization.

\subsection{The Present Classification of Serotonin Receptors}

Based on the general criteria mentioned in Table 2 and in keeping with the above recommendations, serotonin receptors can be subdivided into four main classes $\left(5-\mathrm{HT}_{1}, 5-\mathrm{HT}_{2}, 5-\mathrm{HT}_{3}\right.$ 


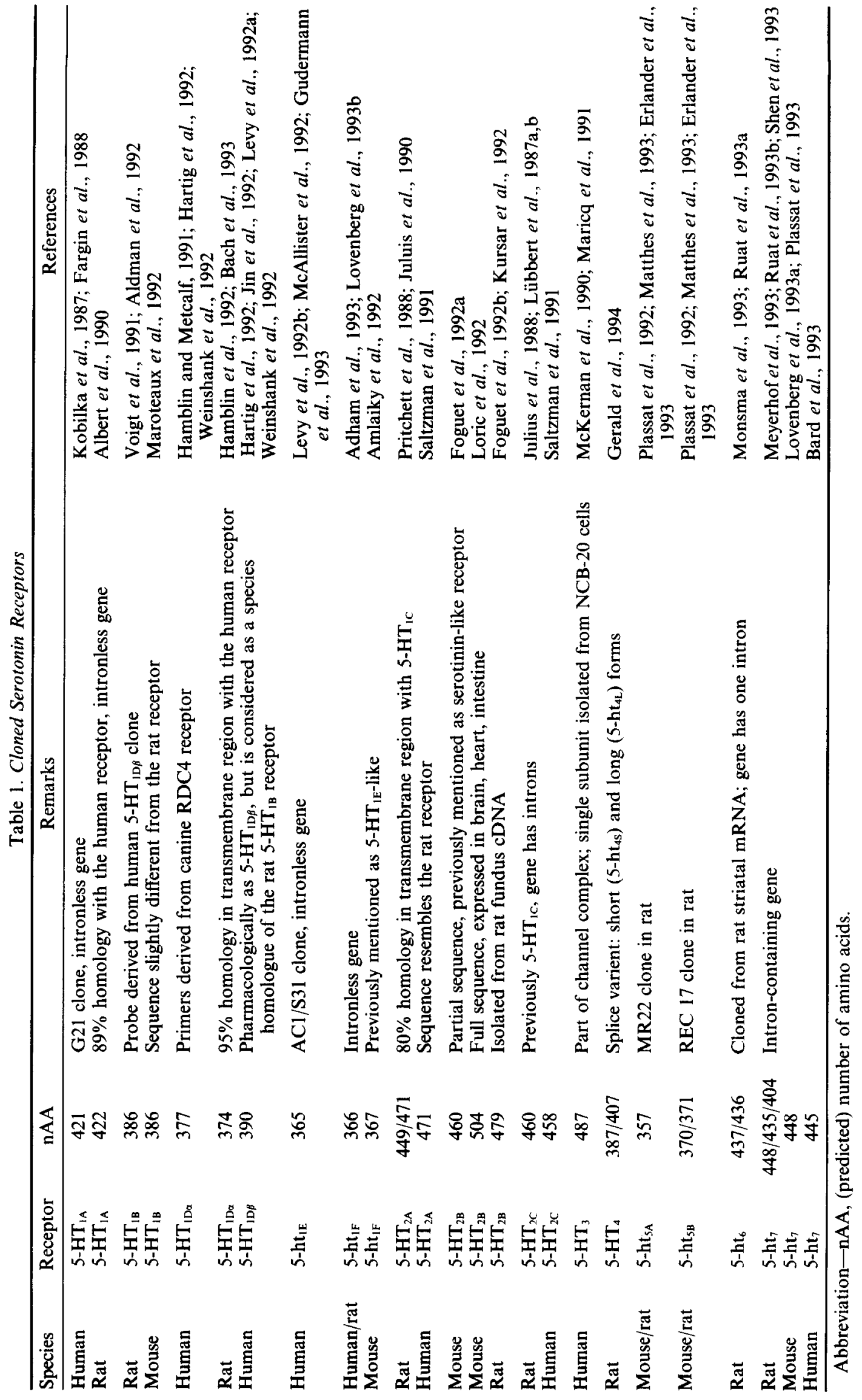




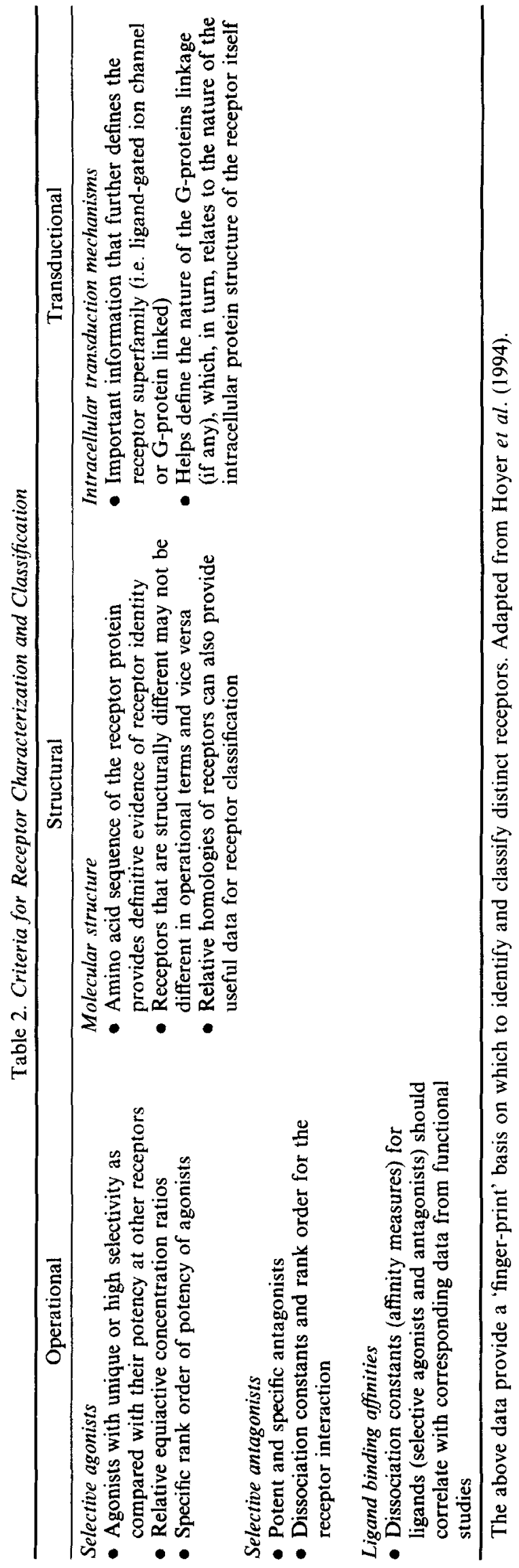




\section{SEROTONIN RECEPTORS}

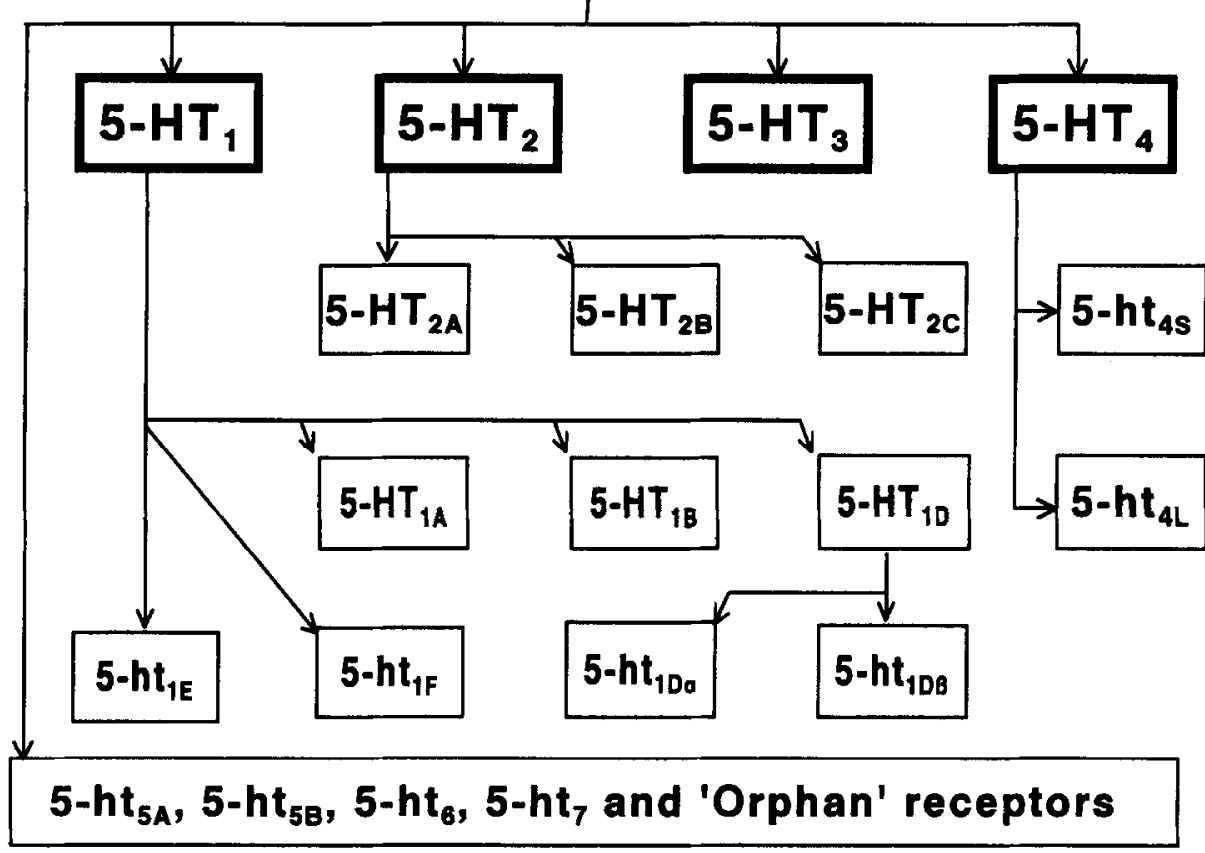

Fig. 3. Subclassification of serotonin receptors. The receptors denoted in lower capital (e.g. 5-ht 6 ) are recombinant receptors, which are not fully characterized yet. The 5 -ht 4 and 5 -ht $\mathrm{HL}_{4 \mathrm{~L}}$ receptors are the short and long splice variants of the $5-\mathrm{ht}_{4}$ receptor.

and 5- $\mathrm{HT}_{4}$ receptors), with certain recombinant (5-ht $\mathrm{I}_{\mathrm{ID} \alpha}, 5-\mathrm{ht}_{\mathrm{ID} \beta}, 5-\mathrm{ht}_{\mathrm{IE}}, 5-\mathrm{ht}_{\mathrm{IF}}, 5-\mathrm{ht}_{4 \mathrm{~S}}, 5-\mathrm{ht}_{4 \mathrm{~L}}, 5-\mathrm{ht}_{5 \mathrm{~A}}$, $5-\mathrm{ht}_{5 \mathrm{~B}}, 5-\mathrm{ht}_{6}$ and $5-\mathrm{ht}_{7}$ ) and 'orphan' receptors (Fig. 3).

The specific operational, structural and transductional properties of the different serotonin receptors are shown in Table 3 (Hoyer et al., 1994). Structurally, all serotonin receptors, except the 5- $\mathrm{HT}_{3}$ receptor, which forms a part of cation channels, belong to the G-protein superfamily and contain the characteristic seven transmembrane regions. All 5- $\mathrm{HT}_{1}$ receptors are negatively coupled to adenylyl cyclase; all 5- $\mathrm{HT}_{2}$ receptors, including the previously called 5- $\mathrm{HT}_{\mathrm{IC}}$ receptor (hence renamed $5-\mathrm{HT}_{2 \mathrm{C}}$ ), are coupled to protein kinase $\mathrm{C}$ via increased phosphoinositide breakdown, while the $5-\mathrm{HT}_{4}, 5-\mathrm{ht}_{6}$ and $5-\mathrm{ht}_{7}$ receptors are positively linked to adenylyl cyclase.

Except for the recombinant subtypes $5-\mathrm{ht}_{\mathrm{IE}}$ and $5-\mathrm{ht}_{\mathrm{IF}}$ (which have been placed in the group based on structural homology and transductional similarity), operationally all other $5-\mathrm{HT}_{1}$ receptors have high affinity for 5-carboxamidotryptamine as agonist and methiothepin as antagonist. It should be noted that such operational criteria also apply to the 'orphan' receptor mediating smooth muscle

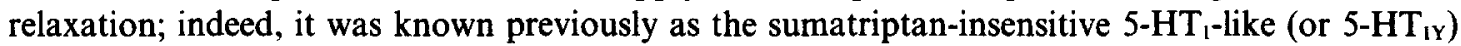
receptor (Bradley et al., 1986; Saxena and Villalón, 1990a). However, in view of its positive coupling to adenylyl cyclase, this receptor, which may turn out to be identical to the recombinant 5 -ht ${ }_{7}$ receptor (Bard et al., 1993; Plassat et al., 1993), has been placed in the 'orphan' category. The 5-HT 1 receptor has a high and selective agonist affinity for flesinoxan, 8-OH-DPAT and dipropyl-5-carboxamidotryptamine, the 5- $\mathrm{HT}_{1 \mathrm{~B}}$ receptor has a high selective agonist affinity for $\mathrm{CP} 93,129$, while both 5-HT $\mathrm{H}_{1 \mathrm{D}}$ and 5- $\mathrm{HT}_{1}$-like receptors have a relatively high affinity for sumatriptan. Selective antagonists have only recently been described for 5-HT 1 (WAY 100135; Fletcher et al., 1993) and 5-HT 1 (GR 127935; Skingle et al., 1993; Clitherow et al., 1994) receptors, and undoubtedly, these will help in further characterization. With regard to the 5-HT - like receptors, it is to be noted that their structure has not been elucidated yet (Table 3) and that these may be heterogeneous (see Saxena and Villalón, 1990a; Hoyer et al., 1994). The operational characteristics of 5-HT - -like receptors resemble those

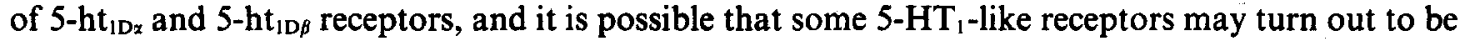
identical to these or other recombinant receptors. 


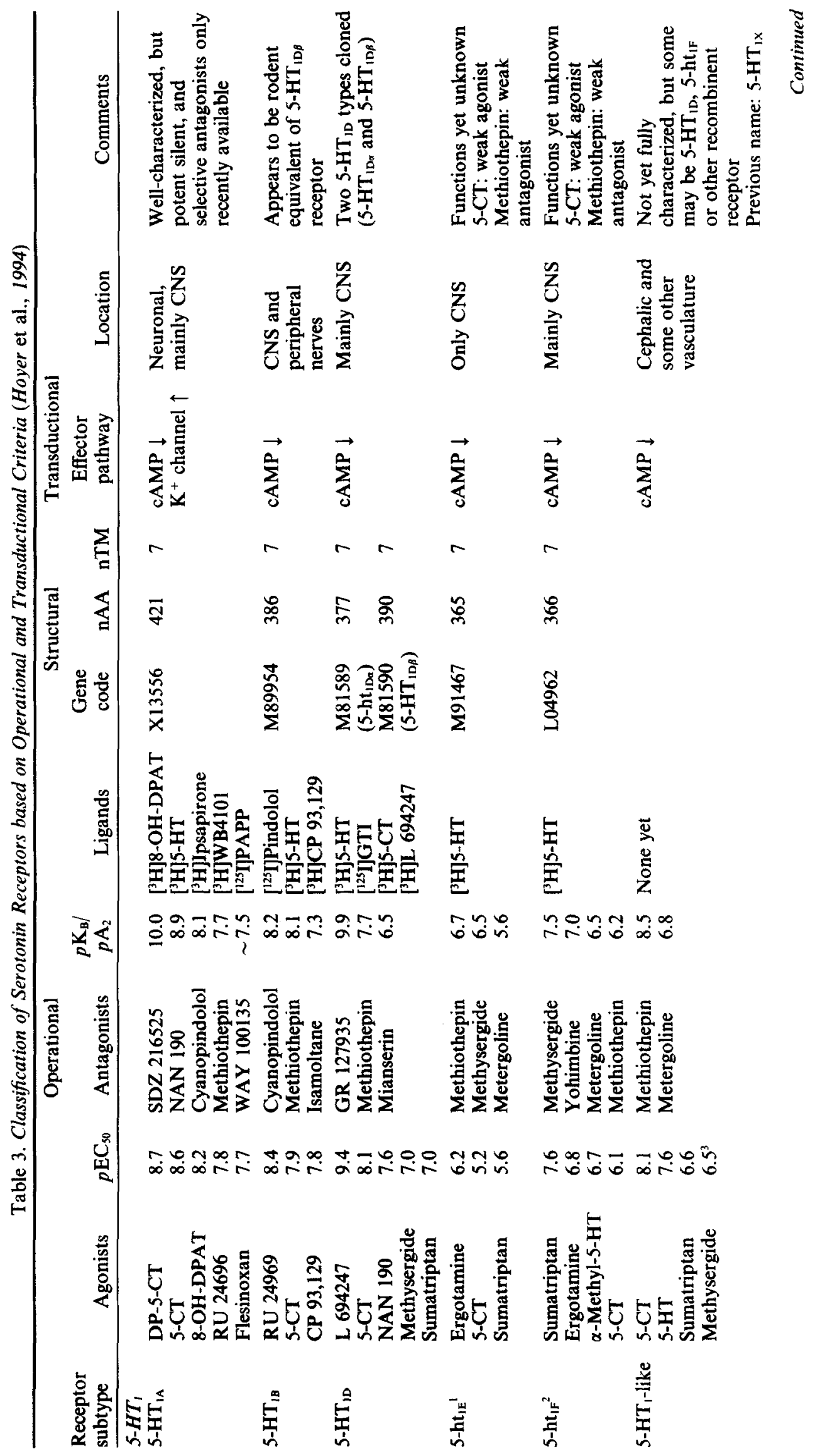




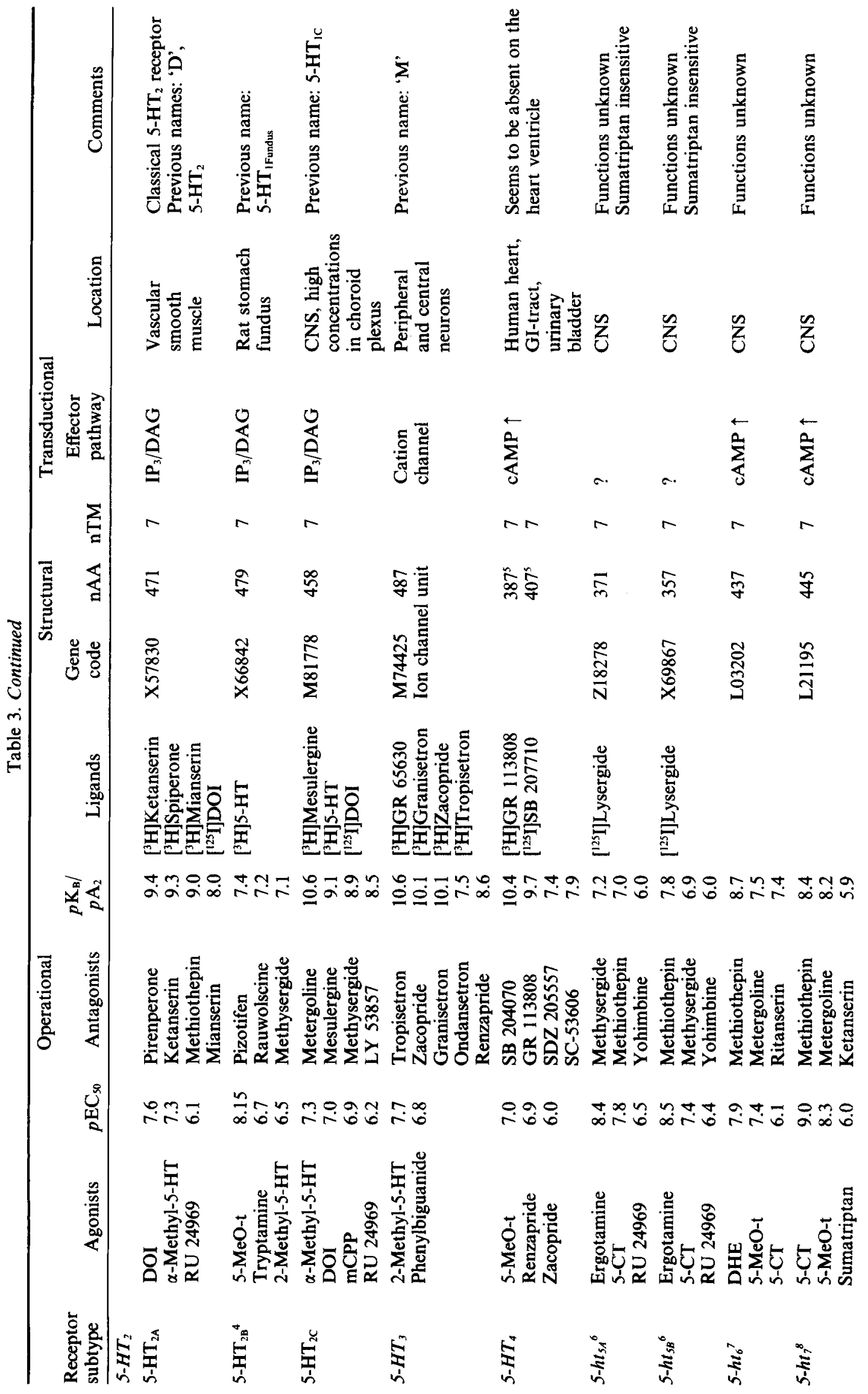




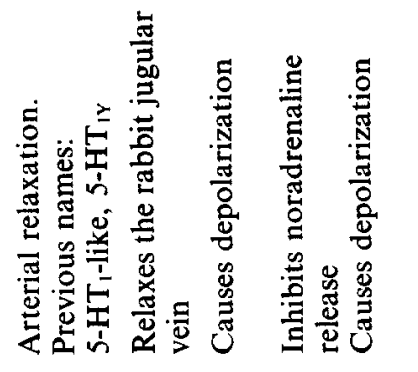

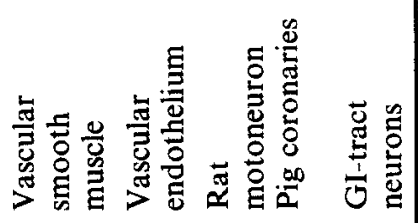

$\stackrel{\leftarrow}{\sum_{0}}$

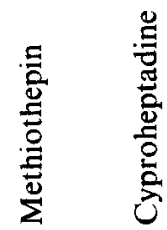

$\bigcup_{i} \quad \stackrel{\infty}{\mathbb{N}}$

$\frac{0}{5}$

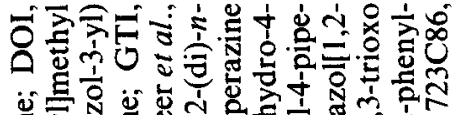

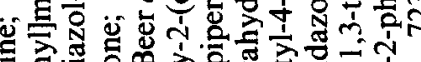

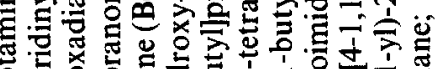

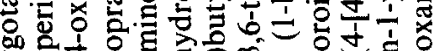

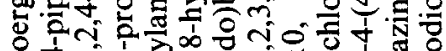

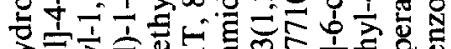

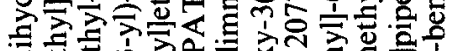

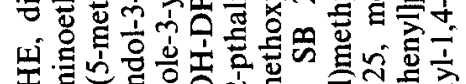

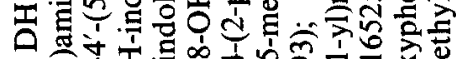

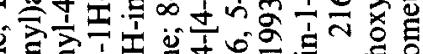

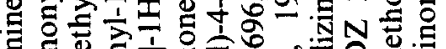

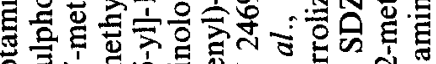

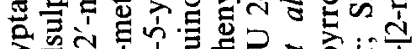

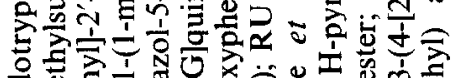

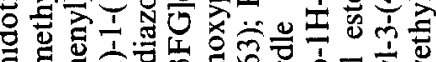

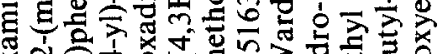

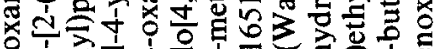

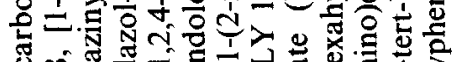

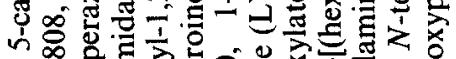

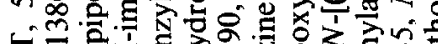

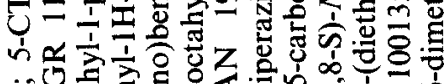

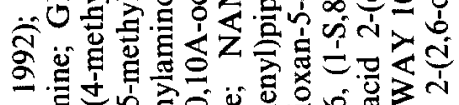

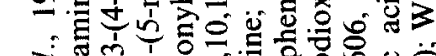

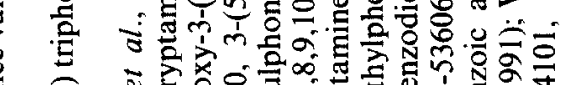

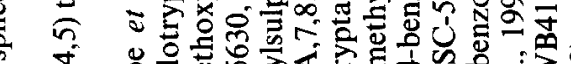

क 吉

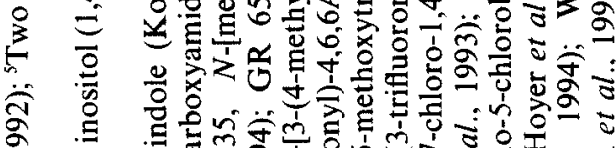

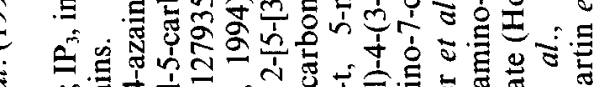

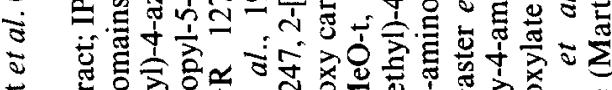

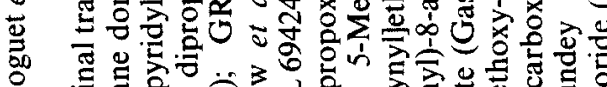

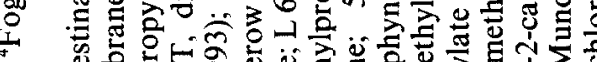

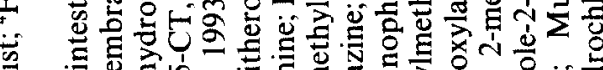

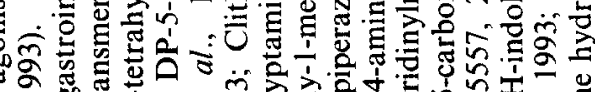

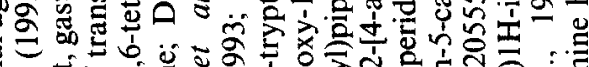

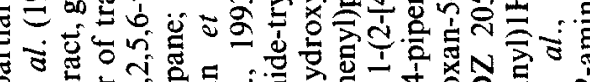

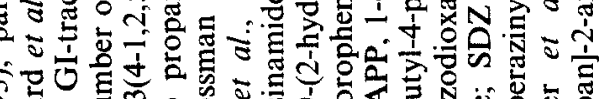

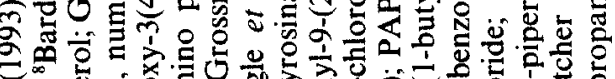

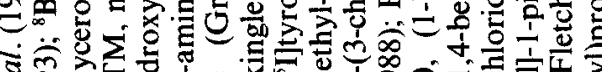

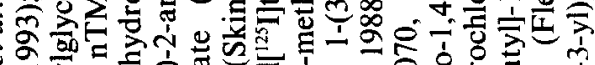

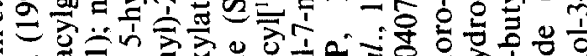

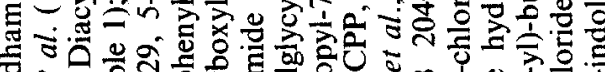

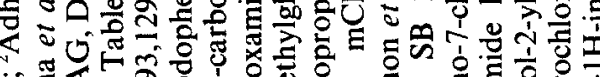

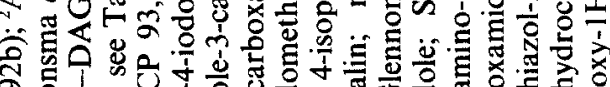

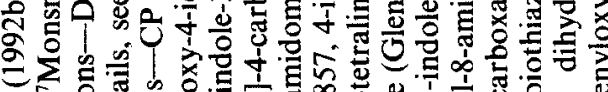

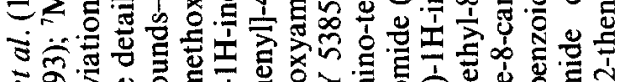

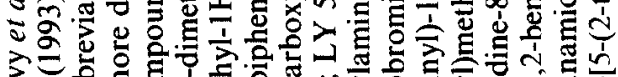

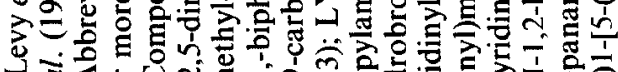

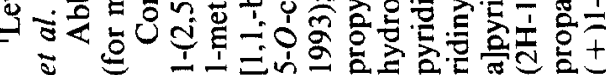


The operational characteristics of 5- $\mathrm{HT}_{2}$ receptor subtypes are similar, but not identical; ketanserin seems to be much more potent at the $5-\mathrm{HT}_{2 \mathrm{~A}}$ receptor than at the two other subtypes. In the case of the $5-\mathrm{HT}_{3}$ and $5-\mathrm{HT}_{4}$ receptors, potent and selective antagonists are now available.

\section{RESPONSES MEDIATED BY SEROTONIN RECEPTORS}

The functional responses associated with the different $5-\mathrm{HT}_{1}$ receptor subtypes are listed in Table 4 . The 5-HT $\mathrm{HA}_{1 \mathrm{~A}}$ receptor stimulation is associated with behavioural changes and a centrally mediated hypotensive response. The 5- $\mathrm{HT}_{1 \mathrm{~B}}$ receptor is present in the rodent $\mathrm{CNS}$ and seems primarily associated with decrease in transmitter release. The same appears to be the case with $5-\mathrm{HT}_{\mathrm{ID}}$ receptors in other mammals. In addition, it is suggested, though not definitely established yet, that stimulation of 5-ht $\mathrm{HD}_{\mathrm{D} x}$ receptor decreases plasma extravasation following trigeminal nerve stimulation (Buzzi et al., 1991; Matsubara et al., 1991), while 5-ht ${ }_{1 \mathrm{D} \beta}$ receptors mediate contraction of cerebral arteries (Hamel et al., 1993). The contraction of cephalic arteries and arteriovenous anastomoses and inhibition of noradrenaline release from sympathetic nerve endings are mediated by $5-\mathrm{HT}_{1}$-like receptors, but some 5- $\mathrm{HT}_{1}$-like receptors may be identical to the 5-HT $\mathrm{H}_{1 \mathrm{D}}$ receptors (Hoyer et al., 1994).

Table 5 present examples of functional responses mediated by $5-\mathrm{HT}_{2}, 5-\mathrm{HT}_{3}$ and $5-\mathrm{HT}_{4}$ receptors. The 5- $\mathrm{HT}_{2 \mathrm{~A}}$ receptor is ubiquitous and mediates mainly contraction of vascular and nonvascular smooth muscles, platelet aggregation and neuroexcitation. The 5- $\mathrm{HT}_{2 \mathrm{~B}}$ receptor has been located primarily in the rat and mouse stomach fundus and mediates contraction. The $5-\mathrm{HT}_{2 \mathrm{C}}$ receptor may regulate the amount and composition of the cerebrospinal fluid, as well as decrease locomotion and appetite. Undoubtedly, the $5-\mathrm{HT}_{3}$ receptor is involved in vomiting resulting from radiation and anticancer drugs. In addition, stimulation of the 5- $\mathrm{HT}_{3}$ receptor, which is a part of a cation channel, results in depolarization of peripheral and central neurons. Stimulation of the 5- $\mathrm{HT}_{4}$ receptor leads to decreases in $\mathrm{K}^{+}$conductance in colliculi neurons and increases in EEG energy. Peripherally, 5- $\mathrm{HT}_{4}$ receptors affect motility of the gastrointestinal tract and mediate increases in the porcine and human atrial rate and contractility (Table 5). Interestingly, 5- $\mathrm{HT}_{4}$ receptors seem to be absent on porcine (Saxena et al., 1992; Schoemaker et al., 1992), as well as human (Jahnel et al., 1992; Schoemaker et al., 1993) ventricles.

The structure of the recombinant $5-\mathrm{ht}_{5 \mathrm{~A}}, 5-\mathrm{ht}_{5 \mathrm{~B}}, 5-\mathrm{ht}_{6}$ and $5-\mathrm{ht}_{7}$ receptors is well-established, and these have been localized mainly in certain areas of the CNS, but the functions mediated are yet to be understood (Table 6). On the other hand, a number of serotonin receptors have been placed in a temporary 'orphan' category, since no structural data and only limited transductional and operational data are available yet (Table 6).

\section{THERAPEUTIC USES OF SEROTONIN RECEPTOR LIGANDS}

There are currently more than 70 pharmaceutical companies with interest in serotonergic drugs, and the leaders, in the rank order of the number of patents filed (and not the revenue earned), are shown in Fig. 4. This patent activity indicates that these companies expect to convert the new chemical entities into marketable products for therapeutic uses. The established, as well as some potential, therapeutic uses of serotonin receptor agonists and antagonists are listed in Table 7.

\subsection{Anxiety States}

The role of serotonin uptake inhibitors, as well as serotonin receptor ligands, in the treatment of anxiety states has been explored extensively (see Charney et al., 1990; Murphy et al., 1993). It appears that $5-\mathrm{HT}_{\mathrm{IA}}$ receptor partial agonists such as buspirone are clinically effective in generalized anxiety disorders and in anxiety associated with depression, but not in panic disorders. The effectiveness of these drugs in obsessive anxiety disorders has been investigated so far in only one controlled trial (see Murphy et al., 1993). Animal experiments suggest that 5-HT $\mathrm{T}_{1 \mathrm{~A}}$ receptors located in the hippocampus, thalamus, amygdala and raphé nuclei are involved in the therapeutic effects of $5-\mathrm{HT}_{1 \mathrm{~A}}$ receptor partial agonists in anxiety (Charney et al., 1990). Clinical results with the recently developed 
Table 4. Examples of Functional Responses Thought to be Mediated by 5-HT, Receptors Subtypes

\begin{tabular}{|c|c|c|c|}
\hline Species & Tissues & Responses & References \\
\hline $\begin{array}{l}5-H T_{1 A} \\
\text { Several }\end{array}$ & Amygdala/raphé & Emotional changes & $\begin{array}{l}\text { Hoyer et al., 1986; Pazos et al., 1987; } \\
\text { Radja et al., 1991 }\end{array}$ \\
\hline Rat & CNS & 'Behaviour syndrome' & Tricklebank, 1985; Lucki, 1992 \\
\hline Cat & CNS & $\downarrow \mathrm{BP}, \downarrow \mathrm{HR}$ & Göthert and Kolassa, 1990 \\
\hline $\begin{array}{l}5-H T_{1 B} \\
\text { Rat }\end{array}$ & Cerebral cortex & $\downarrow 5$-HT release & Middlemiss, 1986; Limberger et al., 1991 \\
\hline Rat & $\begin{array}{l}\text { Basal ganglia and } \\
\text { other CNS areas }\end{array}$ & $\begin{array}{l}\text { Changes in Ach and } \\
\text { glutamate release }\end{array}$ & $\begin{array}{l}\text { Middlemiss, 1986; Engel et al., 1986; } \\
\text { Limberger } \text { et al., } 1991\end{array}$ \\
\hline Rat & Vena cava & NA release & Göthert et al., 1986 \\
\hline Rat & Dura mater & Plasma extravasation & Saito et al., 1988; Matsubara et al., 1991 \\
\hline Rat & Caudal artery & Contraction & Craig and Martin, 1993 \\
\hline $\begin{array}{l}5-H T_{1 D} \\
\text { Guinea-pig }\end{array}$ & Cerebral cortex & 5 -HT release & Middlemiss, 1986 \\
\hline Guinea-pig & Hippocampus & $\mathrm{ACh}$ release & Harpel-Dupas et al., 1991 \\
\hline Guinea-pig & Dura mater & Plasma extravasation & Buzzi et al., $1991^{2}$ \\
\hline & Coronary endothelium & EDRF-release & Schoeffter and Hoyer, 1990 \\
\hline Human & Cerebral arteries & Contraction & Hamel et al., $1993^{3}$ \\
\hline $\begin{array}{l}5-h t_{I E} \\
\text { Human }\end{array}$ & Frontal cortex & Unknown & Leonhardt et al., 1989 \\
\hline Several & CNS areas & Unknown & Beer et al., 1992; Miller and Teitler, 1992 \\
\hline $5-h t_{I F}$ & & & \\
\hline Mouse/rat & CNS, mesentery, uterus & Unknown & $\begin{array}{l}\text { Adham et al., 1993; Lovenberg et al., } \\
\text { 1993b }^{4}\end{array}$ \\
\hline Mouse & Hippocampus & Unknown & Amlaiky et al., $1992^{4}$ \\
\hline $\begin{array}{l}\text { 5-ht } t_{l} \text {-like } \\
\text { Human }\end{array}$ & Saphenous vein & Contraction & $\begin{array}{l}\text { Bax et al., 1992; Glusa and Müller- } \\
\text { Schweinitzer, } 1993\end{array}$ \\
\hline Dog & Saphenous vein & Contraction & $\begin{array}{l}\text { Sumner and Humphrey, 1990; Müller- } \\
\text { Schweinitzer, 1990; Sumner et al., } 1992\end{array}$ \\
\hline Rabbit & Saphenous vein & Contraction & $\begin{array}{l}\text { Martin and MacLennan, 1990; Van } \\
\text { Heuven-Nolsen et al., } 1990\end{array}$ \\
\hline Human & Pial arteries & Contraction & Hamel and Bouchard, 1991 \\
\hline Human & Basilar artery & Contraction & Parsons et al., 1989 \\
\hline Monkey & Basilar artery & Contraction & Connor et al., 1989b \\
\hline Pig & Basilar artery & Contraction & Van Charldorp et al., 1990 \\
\hline Dog & Basilar artery & Contraction & Connor et al., $1989 \mathrm{~b}$ \\
\hline Guinea-pig & Basilar artery & Contraction & Chang and Owman, 1989 \\
\hline Pig & Carotid AVÁs & Constriction & Saxena et al., 1986, 1989 \\
\hline Human & Coronary artery & Contraction & $\begin{array}{l}\text { Connor et al., 1989a; Chester et al., 1990; } \\
\text { Bax et al., } 1993\end{array}$ \\
\hline Rabbit & Renal artery & Contraction & Tadipatri et al., 1991, 1992 \\
\hline Guinea-pig & Iliac artery & Contraction & $\begin{array}{l}\text { Sahin-Erdemli et al., 1991; Schoeffter } \\
\text { and Sahin-Erdemli, } 1992\end{array}$ \\
\hline Human & Saphenous vein & $\downarrow$ NA release & Moldering et al., 1990 \\
\hline Dog & Saphenous vein & INA release & Fenuik et al., 1979; Watts et al., 1981 \\
\hline
\end{tabular}

${ }^{1}$ Based on Saxena and Villalón (1990a) and Hoyer et al. (1994); ${ }^{2}$ claimed to resemble 5-HT ${ }_{1 D_{z}}$ subtype; ${ }^{3}$ claimed to resemble $5-\mathrm{HT}_{1 \mathrm{D} \beta}$ subtype; ${ }^{4}$ mentioned as $5-\mathrm{HT}_{1 \mathrm{E} \beta}$ or $5-\mathrm{HT}_{\mathrm{IE}}$-like.

Abbreviations--Ach, acetylcholine; AVAs, arteriovenous anastomoses; BP, arterial blood pressure; EDRF, endothelium-derived relaxant factor (probably nitric oxide); HR, heart rate; NA, noradrenaline.

'silent' 5-HT $\mathrm{HA}_{1 \mathrm{~A}}$ receptor antagonists, such as WAY 100135 (Fletcher et al., 1993), are awaited with interest to settle the question whether an agonist or antagonist activity is important in the anti-anxiety effect.

Some preliminary clinical trials suggest that $5-\mathrm{HT}_{2}$ and $5-\mathrm{HT}_{3}$ receptor antagonists may have a beneficial effect in generalized anxiety disorder patients (Murphy et al., 1993; Greenshaw, 1993). 
Table 5. Examples of Functional Responses Thought to be Mediated by 5-HT2, 5-HT $T_{3}$ and 5-HT $T_{4}$ Receptors $^{1}$

\begin{tabular}{|c|c|c|c|}
\hline Species & Tissues & Responses & References \\
\hline \multicolumn{4}{|l|}{$5-H T_{2}$} \\
\hline Rat & Raphé cell bodies & Neuroexcitation & North and Uchimura, 1989 \\
\hline Monkey & Pituitary & Prolactin release & Heninger et al., 1987 \\
\hline Dog & Adrenal medulla & Catecholamine release & Humphrey and Feniuk, 1987 \\
\hline Several & Many blood vessels & Contraction & $\begin{array}{l}\text { Bradley et al., 1986; Saxena and } \\
\text { Villalón, } 1990 \mathrm{a}\end{array}$ \\
\hline Several & Bronchial smooth muscle & Contraction & Bradley et al., 1986 \\
\hline Several & Uterine smooth muscle & Contraction & Bradley et al., 1986 \\
\hline Guinea-pig & Ileal smooth muscle & Contraction & $\begin{array}{l}\text { Gaddum and Picarelli, 1957; Bradley } \\
\text { et al., } 1986\end{array}$ \\
\hline Several & Blood platelets & Aggregation & Bradley et al., 1986 \\
\hline \multicolumn{4}{|l|}{$5-H T_{2 B}$} \\
\hline Mouse/rat & Stomach fundus & Contraction & Foguet et al., 1992; Kursar et al., 1992 \\
\hline Rat & Gut, heart, lung & Unknown & Foguet et al., 1992 \\
\hline \multicolumn{4}{|l|}{$5-H T_{2 C}$} \\
\hline Several & Choroid plexus & CSF composition? & $\begin{array}{l}\text { Pazos et al., 1984; Yagalof and Hartig, } \\
1985\end{array}$ \\
\hline Rat & CNS areas & $\downarrow$ Motion, feeding & Curzon and Kennett, 1990 \\
\hline \multicolumn{4}{|l|}{$5-H T_{3}$} \\
\hline Several & CNS areas & $\begin{array}{l}\text { Not well understood, } \\
\text { radiation vomiting, } \\
\text { changes in cognition } \\
\text { psychosis, drug craving }\end{array}$ & $\begin{array}{l}\text { Kilpatrick et al., 1987, 1990; Weber } \\
\text { et al., 1989; Hamon et al., 1989; } \\
\text { Laporte et al., } 1992\end{array}$ \\
\hline Several & Baro/chemoreceptors & $\begin{array}{l}\text { Bezold-Jarisch reflex, } \\
\text { radiation vomiting }\end{array}$ & $\begin{array}{l}\text { Fozard, 1990; Saxena and Villalón, } \\
\text { 1990a }\end{array}$ \\
\hline Several & Peripheral neurons & $\begin{array}{l}\text { Depolarization } \\
\text { transmitter release }\end{array}$ & $\begin{array}{l}\text { Fozard, 1990; Saxena and Villalón, } \\
\text { 1990a }\end{array}$ \\
\hline Cat & Parasympathetic neurons & $\begin{array}{l}\text { Urinary bladder/gut } \\
\text { contraction }\end{array}$ & $\begin{array}{l}\text { Fozard, 1990; Saxena and Villalón, } \\
\text { 1990a }\end{array}$ \\
\hline Human & Skin neurons & Pain and flare & Orwin and Fozard, 1986 \\
\hline \multicolumn{4}{|l|}{$5-H T_{4}$} \\
\hline Mouse & Colliculi neurons & $\downarrow \mathbf{K}+$ conductance & Demuis et al., 1988; Fagni et al., 1992 \\
\hline Rat & CNS & $\uparrow$ EEG-energy & Boddeke and Kalkman, 1990 \\
\hline Guinea-pig & Myenteric neurons & $\uparrow$ Fast EPSP & Tonini et al., 1989 \\
\hline Guinea-pig & Ileum & Contraction/peristalsis & $\begin{array}{l}\text { Craig et al., 1990; Buchheit and Buhl, } \\
1991\end{array}$ \\
\hline Guinea-pig & Colon & Contraction & $\begin{array}{l}\text { Elswood et al., 1991; Wardle and } \\
\text { Sanger, } 1993\end{array}$ \\
\hline Rat & Ileum & Relaxation & Tuladhar et al., 1991, 1992 \\
\hline Rat & Oesophagus & Relaxation & $\begin{array}{l}\text { Baxter et al., 1991a; Reeves et al., } \\
\text { 1991; Ford et al., } 1992\end{array}$ \\
\hline Human & Colon circular muscle & Contraction & $\begin{array}{l}\text { Baxter et al., 1991b; Tam et al., 1992; } \\
\text { McLean et al., } 1993\end{array}$ \\
\hline Human & Ileal musosa & $\uparrow$ Short-circuit current & Burleigh and Brown, 1993 \\
\hline Monkey & Urinary bladder & Relaxation & Waiker et al., 1994 \\
\hline Human & Urinary bladder & Contraction & Corsi et al., 1991 \\
\hline Human & Adrenal cortex & Aldosterone release & Lefebvre et al., 1993 \\
\hline Piglet & Atria & $\uparrow$ Rate and force & Kaumann, $1990^{2}$ \\
\hline Pig & Heart & $\uparrow$ Heart rate & $\begin{array}{l}\text { Saxena, 1986; Villalón et al., } 1990 \text {, } \\
1991^{2}\end{array}$ \\
\hline Human & Atrial appendage & $\uparrow$ Force & Kaumann et al., $1990,1991^{3}$ \\
\hline
\end{tabular}

'Based on Hoyer et al . (1994); ${ }^{2}$ porcine ventricles lack 5-HT 4 receptors (Saxena et al., 1992; Schoemaker et al., 1992); ' human left ventricles lack 5-HT 4 receptors (Jahnel et al., 1992; Schoemaker et al., 1993).

Abbreviations-CSF, cerebrospinal fluid; EPSP, excitatory postsynaptic potential. 
Table 6. Examples of Functional Responses Thought to be Mediated by other Serotonin Receptors

\begin{tabular}{|c|c|c|c|}
\hline Species & Tissues & Responses & References \\
\hline $\begin{array}{l}5-H T_{5 A / B} \\
\text { Mouse/rat }\end{array}$ & CNS areas & Unknown & $\begin{array}{l}\text { Plassat et al., 1992; Matthes et al., 1993; } \\
\text { Erlander et al., } 1993\end{array}$ \\
\hline $\begin{array}{l}5-h t_{6} \\
\text { Rat }\end{array}$ & Striatum & Unknown & Monsma et al., 1993; Ruat et al., 1993a \\
\hline $\begin{array}{l}5-h t_{7} \\
\text { Rat } \\
\text { Rat }\end{array}$ & $\begin{array}{l}\text { Hypothalamus/thalamus } \\
\text { Cerebellum, heart, gut }\end{array}$ & $\begin{array}{l}\text { Unknown } \\
\text { Unknown }\end{array}$ & $\begin{array}{l}\text { Lovenberg et al., 1993a } \\
\text { Plassat et al., } 1993\end{array}$ \\
\hline \multicolumn{4}{|c|}{$\begin{array}{l}\text { 'Orphan' receptors } \\
\text { 'Orphan' (Vascular smooth muscle) }\end{array}$} \\
\hline Several & Vascular smooth muscle & Relaxation & $\begin{array}{l}\text { Bradley et al., 1986; Saxena and Villalón, } \\
\text { 1990a }\end{array}$ \\
\hline Pig & Vena cava & Relaxation & Trevethick et al., 1986; Sumner, 1991 \\
\hline Cat & Saphenous vein & Relaxation & Humphrey and Fenuik, 1987 \\
\hline Rabbit & Jugular vein & Relaxation & Martin et al., 1987 \\
\hline Pig & Carotid arterioles & Relaxation & Saxena et al., 1986, 1989 \\
\hline Cat & Heart & $\uparrow$ Heart rate & Saxena et al., 1985; Connor et al., 1986 \\
\hline \multicolumn{4}{|c|}{ 'Orphan' (Vascular endothelium) } \\
\hline Several & Vascular endothelium & EDRF release & Saxena and Villalón, 1990a \\
\hline Rabbit & Jugular vein & Relaxation & Leff et al., 1987; Martin et al., 1987 \\
\hline Pig & Vena cava & Relaxation & Sumner, 1991 \\
\hline Pig & Pulmonary artery & Relaxation & Glusa, 1992 \\
\hline Chick & Jugular vein & Relaxation & Imaizumi et al., 1984 \\
\hline \multicolumn{4}{|c|}{ 'Orphan' (Rat motoneuron) } \\
\hline Rat & Spinal motoneuron & Depolarization & Connell and Wallis, 1989 \\
\hline \multicolumn{4}{|c|}{ 'Orphan' (Sympathetic neurons) } \\
\hline Pig & Coronary artery & $\downarrow$ NA release & Molderings et al., 1989 \\
\hline \multicolumn{4}{|c|}{ 'Orphan' $\left(5-H T_{I P}\right)$} \\
\hline Several & Enteric neurons & $\begin{array}{l}\text { Slow depolarization, } \\
\downarrow \text { Ach release }\end{array}$ & Gershon et al., 1991; Frieling et al., 1991 \\
\hline
\end{tabular}

Abbreviations-Ach, acetylcholine; EDRF, endothelium-derived relaxant factor (probably nitric oxide); NA, noradrenaline.

Based on Saxena and Villalón (1990a) and Hoyer et al. (1994).

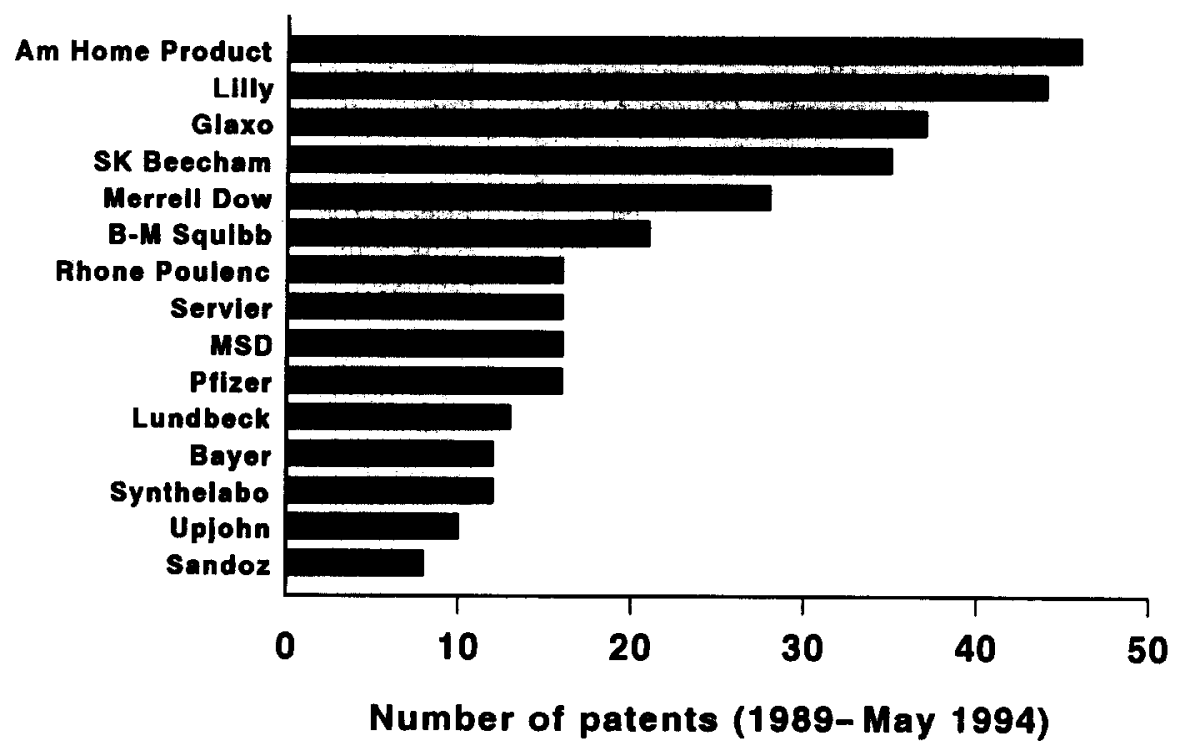

Fig. 4. Pharmaceutical companies with highest number of patents in the serotonin field (Anonymous, 1994). 
Table 7. Some Therapeutic uses of Drugs Acting at Serotonin Receptors

\begin{tabular}{|c|c|c|c|}
\hline Drug & Disease & Status & References \\
\hline \multicolumn{4}{|c|}{ 5-HT $T_{1 A}$ receptor (partial) agonists } \\
\hline Buspirone & Anxiety & Marketed & $\begin{array}{l}\text { Goldberg and Finnerty, 1979; Goa and } \\
\text { Ward, } 1986\end{array}$ \\
\hline Ipsapirone & Anxiety & Clinical phase 3 & Glasser, 1988 \\
\hline Gepirone & Anxiety & Clinical phase 3 & Costello et al., 1991; Pecknold et al., 1993 \\
\hline Urapidil ${ }^{1}$ & Hypertension & Marketed & $\begin{array}{l}\text { Ramage, 1986; Kolassa et al., 1993; Saxena } \\
\text { and Villalón, 1990b }\end{array}$ \\
\hline
\end{tabular}

S-HT $T_{14}$ receptor antagonists

WAY 100135 Anxiety

5-HT,-like/5-HT $T_{1 D}$ receptor antagonists

Sumatriptan Migraine

Naratriptan Migraine

BW311C Migraine

MK-462 Migraine

5-HT

GR127935 Depression

Preclinical

Fletcher et al., 1993

Marketed

Clinical phase 3

Clinical phase 2

Clinical phase 2

Preclinical

Skingle et al., 1993

S-HT $T_{24}$ receptor antagonists

Ketanserin $^{1}$ Hypertension

Ritanserin and Anxiety, psychosis,

Risperidone Sleep disorders

Methysergide $^{2} \quad$ Migraine

Pizotifen $^{2} \quad$ Migraine

5-HT $T_{2 C}$ receptor antagonists

SB 200646 Feeding disorders

SB 200646

Migraine

Marketed

Clinical phase 3

Marketed

Marketed

Preclinical

Preclinical

Marketed

Marketed

Marketed

Clinical phase 2

Ineffective

Preclinical

Clinical phase 2

Clinical phase 2

Ferrari and Saxena, 1993; Saxena and

Tfelt-Hansen, 1993; Welch, 1993

Connor et al., 1993; Perren et al., 1993

Robertson et al., 1991

Beer et al., 1994; Shepheard et al., 1994

McGourty et al., 1985; Saxena and Wouters, 1990

Westernberg and Dan Boer, 1989; Castelao

et al., 1989

Saxena and Den Boer, 1991

Saxena and Den Boer, 1991

Kennett, 1993

Fozard and Gray, 1989; Kennett, 1993

Grunberg et al., 1990; Marty et al., 1990

Chevallier et al., 1990

Dogliotti et al., 1990

Costall et al., 1993

Ferrari, 1991; Ferrari et al., 1991

Hagan et al., 1993

Hagan et al., 1993

Preston et al., 1992
5- $\mathrm{HT}_{4}$ receptor agonists

$\begin{array}{ll}\text { Cisapride } & \text { Gastric motility } \\ \text { Renzapride } & \text { Gastric motility } \\ \text { SC } 49518 & \text { Gastric motility }\end{array}$ $\begin{array}{ll}\text { Marketed } & \text { Briejer } \text { et al., } 1993 \\ \text { Clinical phase 3 } & \text { King et al., 1993b } \\ \text { Preclinical } & \text { Gullikson et al., 1993 }\end{array}$

Preclinical Oxford, 1993

Preclinical
Kaumann and Sanders, 1994
5- $\mathrm{HT}_{4}$ receptor antagonists

SB $207710 \quad$ Cardiac arrhythmias

apparently more important; ${ }^{2}$ other actions are involved; ${ }^{3}$ other properties probably are also involved.

Abbreviations - IBS, irritable bowel syndrome.

Compounds--BW311C, $N, N$-dimethyl-2-[5-(2-oxo-1,3-oxazolidin-4-yl-methyl)-1H-indol-3-yl]-ethylamine; GR 125487, [1-[2-[(methylsulphonyl)amino]ethyl]-4-piperidinyl]methyl-5-fluoro-2-methoxy-1H-indole-3-carboxylate hydrochloride; GR 127935, $N$-[methoxy-3-(4-methyl-1-piperazinyl)-phenyl]-2'-methyl-4'-(5 methyl 1,2,4-oxadiazol-3-yl) [1,1,-biphenyl]-4-carboxamide; MK-462, $N, N$,-dimethyl-2-[5-(1,2,4-triazol-1-yl-methyl)1H-indol 3-yl]ethylamine; SB 200646, $N$-(1-methyl-5-indoyl)- $N$-(3-pyridol urea hydrochloride) (Forbes et al., 1993); SB 207710, [(1-butyl-4-piperidinylmethyl)-8-amino-7-iodo-1,4-benzodioxan-5-carboxylate]; SC 49518, $N$-[exo-(hexahydro-1H-pyrrolizine-1-yl]-2-methoxy-4-amino-5-chlorobenzamide hydrochloride; 100135, $N$-tert-butyl-3-(4-[2-methoxyphenyl]piperazin-1-yl)-2-phenylpropanamide dihydrochloride.

WAY 
However, the evidence so far is far from compelling, and the results of larger placebo-controlled clinical trials are awaited.

\subsection{Other Central Nervous System Diseases}

Drugs acting on serotonin receptors can have potential use in several other CNS diseases, like depression, schizophrenia, memory impairment, sleep disorders and substance abuse (see Table 7). Since $5-\mathrm{HT}_{\mathrm{ID}}$ receptors have been located at serotonergic nerves and can inhibit the transmitter release, antagonists at these autoreceptors may increase serotonin release and, thus, have antidepressant activity. The 5- $\mathrm{HT}_{2}$ receptor antagonists, ritanserin and risperidone, which also blocks dopamine receptors, are being explored for use in psychosis and sleep disorders (Castelao et al., 1989; Westenberg and Den Boer, 1989; Min et al., 1993). Lastly, clinical investigations with 5-HT 3 receptor antagonists are being performed in schizophrenia, substance abuse and memory impairment (see Preston et al., 1992; Costall et al., 1993; Greenshaw, 1993; Hagan et al., 1993). Results of more extensive and controlled clinical trials are awaited with great interest.

\subsection{Migraine}

A large number of studies has shown conclusively that sumatriptan, an agonist at 5-HT - -like receptors, is cffective in aborting migraine attacks (see Ferrari and Saxena, 1993; Saxena and Tfelt-Hansen, 1993; Welch, 1993). The success of this drug, both in a clinical and economic sense, has prompted a large number of pharmaceutical companies-Bristol-Myers Squibb (Smith et al., 1992), Glaxo (Connor et al., 1993; Johnson and North 1993; Perren et al., 1993), Merck Sharp and Dohme (Baker et al., 1994), Merrel Dow (McDonald et al., 1992), Wellcome Foundation (King et al., 1993a) and others-to try to develop novel 5-HT, -like receptor agonists. In particular, the efforts are directed to make more lipid-soluble and selective compounds to improve oral bioavailability and avoid coronary artery vasoconstriction. High lipid solubility can turn out to be a double-edged weapon, since such molecules, unlike sumatriptan (Dallas et al., 1989), would be expected to readily cross the blood-brain barrier and may then be associated with a higher incidence of unwanted effects. For example, in the case of compounds with a similar receptor profile as sumatriptan, the 5-HT $\mathrm{H}_{\mathrm{A}}$ receptor agonism may lead to hypotension and bradycardia (see Saxena and Villalón, 1990a,b).

It is argued sometimes that sumatriptan owes its therapeutic activity solely to a presynaptic action, which inhibits neuropeptide releases and, therefore, 'neurogenic' inflammation (Moskowitz, 1993). Though this view is not shared universally (see Saxena and Ferrari, 1989; Humphrey and Feniuk, 1991; Ferrari and Saxena, 1993; Saxena and Tfelt-Hansen, 1993), it is of interest to note that $\mathrm{NK}_{1}$ receptor antagonists, such as RP 67580 (Shepheard et al., 1993), have been found far more potent than 5-HT $\mathrm{HB}_{\mathrm{B} ; \mathrm{D}}$ receptor agonists (CP 93,129 and sumatriptan) in blocking neurogenic plasma extravasation following trigeminal ganglion stimulation. Should such compounds prove effective as antimigraine agents, the involvement of 'neurogenic' inflammation in migraine will have a stronger footing, though it will not be regarded as an argument against the involvement of vascular mechanisms (Saxena and Ferrari, 1989; Humphrey and Feniuk, 1991; Ferrari and Saxena, 1993; Saxena and Tfelt-Hansen, 1993).

Some antimigraine drugs are potent antagonists at $5-\mathrm{HT}_{2 \mathrm{~A}}$ receptors (methysergide, pizotifen, ergotamine, dihydroergotamine), but many other such agents (ketanserin, ritanserin, cyproheptadine, mianserin, methiothepin, metergoline, sergolexole, ICI 169,369) have not been found of much use in migraine therapy (Winther, 1985; Davies and Steiner, 1990; Tfelt-Hansen and Pedersen, 1992; Tfelt-Hansen and Saxena, 1993). It seems, therefore, that additional properties of these antimigraine drugs, for example, the vasoconstriction in the extracerebral cephalic circulation with methysergide, ergotamine and dihydroergotamine (partly via 5 -HT,-like receptors) and the antidepressant action with pizotifen, may be involved in their therapeutic action (Saxena and Den Boer, 1991). Based mainly on the ability of a $5-\mathrm{HT}_{2 \mathrm{C}}$ receptor agonist, $m$-chloro-phenyl piperazine, to elicit migraine-like headaches in some patients and the ability of drugs such as mianserin to block this receptor, it has been advocated that $5-\mathrm{HT}_{2 \mathrm{C}}$ receptor antagonism is important for antimigraine action (Fozard and Gray, 1989; Fozard, 1992; Kennett, 1993). It should be noted, however, that 
$m$-chloro-phenyl-piperazine is not a selective agent and drugs that block the 5- $\mathrm{HT}_{2 \mathrm{C}}$ receptor (e.g. mianserin, sergolexole) are not particularly effective against migrainous headaches. Moreover, rather than being antagonists, the antimigraine drugs ergotamine and dihydroergotamine behave as potent agonists at the 5-HT $2 \mathrm{C}$ receptor (Brown et al., 1991).

Despite the fact that many $5-\mathrm{HT}_{3}$ receptor antagonists are known for several years and three of them (ondansetron, granisetron and tropisetron) are in clinical use for the treatment of vomiting induced by anticancer drugs, only two such drugs (MDL 72222 and granisetron) have been reported to be effective in migraine (Loisy et al., 1985; Couturier et al., 1991). Though MDL 72222 was studied in a double-blind, placebo-controlled manner (Loisy et al., 1985), this study has been flawed on several grounds (Ferrari, 1991; Ferrari et al., 1991). Granisetron was evaluated in an open study on six patients (Couturier et al., 1991) and, despite encouraging results, this study was discontinued, according to the investigators "for extraneous reasons". On the other hand, carefully designed and extensive investigations with tropisetron, both as acute and prophylactic migraine therapy, were largely negative (Ferrari, 1991; Ferrari et al., 1991). Since no other positive results are known with any of the $5-\mathrm{HT}_{3}$ receptor antagonists, it must be concluded that this receptor does not play a major role in migraine.

The above analysis strongly suggests that within the bounds of serotonergic mechanisms, the antimigraine action mainly depends upon an agonist action at the 5-HT that mediates cephalovascular constriction (Saxena et al., 1993).

\subsection{Vomiting}

Nausea and vomiting are extremely unpleasant side effects of anticancer drugs, and the dopamine $\mathrm{D}_{2}$ receptor antagonists are not very effective as antiemetic agents. Following the report that high doses of metoclopramide, which also blocks 5- $\mathrm{HT}_{3}$ receptors (Bradley et al., 1986; Fozard, 1990), can prevent cisplatin-induced vomiting in cancer patients (Gralla et al., 1981), it was realized that 5- $\mathrm{HT}_{3}$ receptor blockade may play an important role in vomiting (Miner and Sanger, 1986). Indeed, ondansetron (Grunberg et al., 1990; Marty et al., 1990), granisetron (Chevallier et al., 1990) and tropisetron (Dogliotti et al., 1990) have all been shown to successfully suppress the acute phase of vomiting caused by cisplatin; unfortunately, the delayed phase is not much affected (see Wells et al., 1993). The $5-\mathrm{HT}_{3}$ receptor antagonists are selectively effective against vomiting following cancer chemotherapy, radiation exposure or general anaesthesia; these drugs do not prevent vomiting due to other causes, such as motion sickness.

The mechanism of antiemetic action of $5-\mathrm{HT}_{3}$ receptor antagonists appears to be at the level of sensory vagal nerve terminals in the gastrointestinal mucosa, with a possible additional effect at the chemoreceptor trigger zone, where 5- $\mathrm{HT}_{3}$ receptors have also been localized (Kilpatrick et al., 1987; Wells et al., 1993). Microdialysis measurements have clearly shown that cisplatin increases serotonin levels in the ileum, as well as the blood, and such increases are accompanied by vomiting episodes (Fukui et al., 1993).

\subsection{Hypertension}

Both urapidil (5- $\mathrm{HT}_{1 \mathrm{~A}}$ receptor agonist) and ketanserin (5-HT $\mathrm{H}_{2 \mathrm{~A}}$ receptor antagonist) have been approved for the treatment of hypertension. Indeed, it is claimed that these drugs decrease blood pressure by stimulating $5-\mathrm{HT}_{1 \mathrm{~A}}$ receptors located centrally in the nucleus tractus solitarus (urapidil) or by blocking $5-\mathrm{HT}_{2 \mathrm{~A}}$ receptors mediating peripheral vasoconstriction (ketanserin). However, as discussed in detail elsewhere (Saxena and Wouters, 1990), it does not appear that such effects are involved to a significant degree in the clinical effects of these drugs; both urapidil and ketanserin have a potent $\alpha_{1}$-adrenoceptor antagonist activity, which can adequately explain the antihypertensive effect (see Saxena and Villalón, 1990b).

\subsection{Gastric Motility Disorders}

It is well known that high concentrations of serotonin are present in the gastrointestinal tract, where it appears to play an important physiological role in the peristaltic movements (see Gershon 
et al., 1991). Although some progress has been made towards delineation of the nature and function of serotonin receptors in the gastrointestinal tract of several animal species (Dhasmana et al., 1993), the knowledge with regard to the human gut is still scant (Talley, 1992; Tam et al., 1992; McLean et al., 1993). However, 5- $\mathrm{HT}_{3}$ and 5- $\mathrm{HT}_{4}$ receptor antagonists are being explored for therapeutic use in irritable bowel syndrome (Prior and Reed, 1993), since these drugs slow colonic transit in healthy volunteers (Gore et al., 1990; Talley et al., 1990).

The 5-HT 4 receptor agonists seem to have a prokinetic effect (Briejer et al., 1993; Gullikson et al., 1993; King et al., 1993b; Stacher et al., 1993), and their use in reflux oesophagitis (Geldof et al., 1993) and idiopathic (Corinaldesi, 1993) and diabetic (Kawagishi et al., 1993) gastroparesis is being advocated.

\subsection{Pain}

Recent preclinical studies suggest that 5-HT is involved in the mediation of pain, but it has multiple and opposing effects, which depend upon the location and the type of receptor involved (Greenshaw, 1993).

Within the superficial dorsal horn of the spinal cord, a dense band of 5- $\mathrm{HT}_{3}$ receptors has been located on capsaicin-sensitive primary afferent nerve terminals. These 5- $\mathrm{HT}_{3}$ receptors mediate an antinociceptive effect against intrathecal application of substance $\mathrm{P}$ and $N$-methyl-D-aspartate, possibly via $\gamma$-aminobutyric acid reledse (Alhaider $e t a l ., 1991$ ). In contrast, peripheral 5-HT receptors mediate an algesic response following topical application of serotonin on blister base in humans (Richardson et al., 1985; Fozard, 1990).

The nociceptive response to i.v. serotonin may be mediated by both $5-\mathrm{HT}_{2}$ and $5-\mathrm{HT}_{3}$ receptors located on capsaicin-sensitive vagal nerve afferents and, therefore, a combined use of 5-HT2 and $5-\mathrm{HT}_{3}$ receptor antagonists has been suggested for the relief of pain in angina pectoris and other peripheral vascular disorders (Mellor et al., 1992). Interestingly, both 5-HT 1 and 5-HT2 receptors mediate human coronary artery constriction induced by 5-HT (Connor et al., 1989a; Chester et al., 1990; Bax et al., 1993), as well as platelets, even after cyclooxygenase inhibition with aspirin (Bax et al., 1994). Thus, it is advocated that a combined use of 5-HT and 5-HT $\mathrm{H}_{2}$ receptor antagonists may have some role in the treatment of angina pectoris (Bax et al., 1994).

\subsection{Cardiac Disorders}

Increases in the rate and contractility in the human atrium are mediated by $5-\mathrm{HT}_{4}$ receptors (see Table 5). Serotonin can induce arrhythmias in the human isolated atrium and, therefore, 5- $\mathrm{HT}_{4}$ receptor antagonists could be useful in the treatment of cardiac arrhythmias (Kaumann and Sanders, 1994). However, it is not established yet if serotonin plays any role in the pathogenesis of cardiac arrhythmias.

The increase in atrial contractility by $5-\mathrm{HT}_{4}$ receptor agonists indicated that such drugs may have application in the therapy of heart failure. Any such hope has now been dashed, as recent investigations indicate that $5-\mathrm{HT}_{4}$ receptors are not present on human ventricles (Jahnel et al., 1992; Schoemaker et al., 1993).

\section{CLOSING REMARKS}

During the last decade, research in the field of serotonin has been boosted by the availability of potent and selective drug tools. These drug tools and increasing understanding of the transduction mechanisms, as well as the structure of the receptor protein, have enabled the characterization and nomenclature of serotonin receptors in a more meaningful way. Thus, four main classes with several subtypes $\left(5-\mathrm{HT}_{1}, 5-\mathrm{HT}_{2}, 5-\mathrm{HT}_{3}, 5-\mathrm{HT}_{4}\right.$ ), as well as some recombinant (e.g. 5-ht $5 \mathrm{~A}, 5-\mathrm{ht}_{5 \mathrm{~B}}, 5-\mathrm{ht}_{6}, 5-\mathrm{ht}_{7}$; note the use of lower case alphabets) and 'orphan' serotonin receptors, have been recognized. The suggestions made by the Nomenclature Committee of the Serotonin Club and the criteria used in classifying serotonin receptors undoubtedly will be helpful to other groups involved in the classification of pharmacological receptors. 
The molecular cloning and expression of a growing number of serotonin receptors in host cells now offers the possibility to screen new molecules relatively easily in order to recognize more selective ligands. However, this development poses new challenges. Obviously, one of the challenges involves the understanding of the precise function of the recombinant receptors at the various anatomical locations. Secondly, it may be asked why should there be so many serotonin receptor subtypes in the body. Is it that each receptor subtype mediates a specific function, or is it that more than one receptor subtype mediates the same function, perhaps under different circumstances, thus providing 'receptor backup'? The answers will dictate the strategy with regard to the degree of selectivity in developing therapeutically relevant molecules.

The responses mediated via many serotonin receptors are now well understood, and this, in turn, has resulted in the development and use of serotonergic drugs in the therapy of several diseases, including anxiety and migraine. Given the pace with which new knowledge is emerging, therapeutic potentials of serotonin-based drugs will undoubtedly be exploited further. The availability of newer and more selective serotonin ligands will help us better define the role of serotonin and its receptors in physiological processes and pathophysiological mechanisms. This knowledge, in turn, will provide access to better drugs for treatment of human ailments more efficiently. Thus, the future of serotonin research looks as bright as ever.

\section{REFERENCES}

Adham, N., Romanienko, P., Hartig P., Weinshank, R. L. and Branchek, T. (1992) The rat 5 -hydroxytryptamine ${ }_{1 B}$ receptor is the species homologue of the human 5-hydroxytryptamine ${ }_{1 \mathrm{D} \beta}$ receptor. Molec. Pharmac. 41: 1-7.

Adham, N., Kao, H.-T., Schechter, L. E., Bard, J., Olsen, M., Urquhart, D., Durkin, M., Hartig, P. R., Weinshank, R. L. and Branchek, T. L. (1993) Cloning of another human serotonin receptor (5- $\mathrm{HT}_{\mathrm{IF}}$ ): a fifth 5-HT, receptor sub-type coupled to the inhibition of adenylyl cyclase. Proc. natn. Acad. Sci. U.S.A. 89: 408-412.

$\Lambda$ dham, N., Gerald, C., Vaysse, P. J., Weinshank, R. L. and Branchek, T. A. (1994) Characterization of the functional responses mediated by two splice variants of the cloned rat $5-\mathrm{HT}_{4}$ receptor in heterologous expression systems. Br.J. Pharmac., in press.

Albert, P. R., Zhou, Q.-Y., van Tol, H. H. M., Bunzow, J. R. and Civelli, O. (1990) Cloning functional expression and messenger RNA tissue distribution of the rat 5-hydroxytryptamine ${ }_{1 \mathrm{~A}}$ receptor gene. J. biol. Chem. 265: $5825-5832$.

Alhaider, A. A., Lei, S. Z. and Wilcox, G. L. (1991) Spinal 5-HT 3 receptor mediated antinociception: possible release of GABA. J. Neurosci. 11: 1881-1888.

Amlaiky, N., Ramboz, S., Boschert, U., Plassat, J. L. and Hen, R. (1992) Isolation of a mouse 5-HT ${ }_{1 \mathrm{E}}-\mathrm{like}$ serotonin receptor expressed predominantly in hippocampus. J. biol. Chem. 267: 19761-19764.

Anonymous (1994) Summary factfile. Curr. Drugs: Serotonin June: SER-1-SER-31.

Bach, A. W. J., Unger, L., Sprengel, R., Mengod, G., Palacios, J., Seeburg, P. H. and Voigt, M. M. (1993) Structurc, functional expression and spatial distribution of a cloned cDN $\Lambda$ encoding a rat $5-\mathrm{HT}_{\mid \mathrm{D}}$-like receptor. J. Recept. Res. 13: 479-502.

Baker, R., Matassa, V. G. and Reeve, A. J. (1994) 4-Substituted 1,2,4-triazole derivatives. Merck Sharp and Dohme Ltd. Patent No. EP-581538.

Bard, J. A., Zgombick, J., Adham, N., Vaysse, P., Branchek, T. A. and Weinshank, R. L. (1993) Cloning of a novel human serotonin receptor $\left(5-\mathrm{HT}_{7}\right)$ positively linked to adenylate cyclase. J. biol. Chem. 268: $23422-23426$.

Bax, W. A., van Heuven-Nolsen, D., Bos, E., Simoons, M. L. and Saxena, P. R. (1992) 5-Hydroxytryptamine-induced contractions of the human isolated saphenous vein: involvement of 5-HT ${ }_{2}$ and 5-HT $1 \mathrm{D}-$ like receptors, and a comparison with 'grafted' veins. Naunyn-Schmiedeberg's Arch. Pharmac. 345: $500-508$.

Bax, W. A., Renzenbrink, G. J., van Heuven-Nolsen, D., Thijssen, E. J. M., Bos, E. and Saxena, P. R. (1993) 5-HT receptors mediating contractions of the isolated human coronary artcry. Eur. J. Pharmac. 239: 203-210.

Bax, W. A., Renzenbrink, G. J., van Der Linden E., Zijlstra, F. J., van Heuven-Nolsen, D., Fekkes, D., Bos, E. and Saxena, P. R. (1994) Low-dose aspirin inhibits platelet-induced contraction of the human isolated coronary artery. A role for additional 5-hydroxytryptamine receptor antagonism against coronary vasospasm? Circulation 89: 623-629.

Baxter, G. S., Craig, D. A. and Clarke, D. E. (1991a) 5-Hydroxytryptamine ${ }_{4}$ receptors mediate relaxation of thc rat ocsophageal tunica muscularis mucosae. Naunyn-Schmiedeberg's Arch. Pharmac. 343: 439-446.

Baxter, G. S., Pritikim, J., Young, H. and Clarke, D. E. (1991b) 5-HT receptors in human ileum and colon. Br. J. Pharmac. 102: 163P.

Beer, M. S., Stanton, J. A., Bevan, Y., Chauhan, N. S. and Middlemiss, D. N. (1992) An investigation of the 
5-HT $\mathrm{T}_{\mathrm{iD}}$ receptor binding affinity of 5-hydroxytryptamine, 5-carboxamidotryptamine and sumatriptan in the central nervous system of seven species. Eur. J. Pharmac. 213: 193-197.

Beer, M. S., Stanton, J. A., Bevan, Y., Heald, A., Reeve, A. J., Street, L. J., Matassa, V. G., Hargrieves, R. J. and Middlemiss, D. N. (1993) L 694247: a potent 5-HT 1 receptor agonist. Br. J. Pharmac. 110: $1196-1200$.

Beer, M. S., Middlemiss, D. N., Stanton, J. A., Longmore, J., Hargrieves, R. J., Noble, A., Scholey, K., Bevan, Y., Hill, R., Baker, R., Street, L., Matassa, V. G. and Iversen, L. (1994) An in vitro pharmacological profile of the novel anti-migraine 5-HT ${ }_{1 D}$ receptor agonist MK-462. In: Abstracts Book, Third IUPHAR Satellite Symposium on Serotonin, Chicago, p. 105.

Bennett, J. P. and Aghajanian, G. K. (1974) D-LSD binding to brain homogenates: possible relationship to serotonin receptors. Life Sci. 15: 1935-1944.

Bennett, J. P. and Snyder, S. H. (1976) Serotonin and lysergic acid diethylamide binding in rat brain membranes: relationship to postsynaptic serotonin receptors. Molec. Pharmac. 12: 373-389.

Boddeke, H. W. G. M. and Kalkman, H. O. (1990) Zacopride and BRL 24924 induce an increase in EEG-energy in rats. Br. J. Pharmac. 101: 281-284.

Bom, A. H., Duncker, D. J., Saxena P. R. and Verdouw, P. D. (1988) 5-Hydroxytryptamine-induced tachycardia in the pig: possible involvement of a new type of 5-hydroxytryptamine receptor. Br. J. Pharmac. 93: 663-671.

Bradley, P. B., Engel, G., Feniuk, W., Fozard, J. R., Humphrey, P. P. A., Middlemiss, D. N., Mylecharane, E. J., Richardson, B. P. and Saxena, P. R. (1986) Proposals for the classification and nomenclature of functional receptors for 5-hydroxytryptamine. Neuropharmacology 25: 563-576.

Briejer, M. R., Akkermans, L. M., Meulemans, A. L., Lefebvre, R. A. and Schuurkes, J. A. (1993) Cisapride and a structural analogue, $\mathrm{R} 76,186$, are 5-hydroxytryptamine ${ }_{4}\left(5-\mathrm{HT}_{4}\right)$ receptor agonists on the guinea-pig colon ascendens. Naunyn-Schmiedeberg's Arch. Pharmac. 347: 464-470.

Brown, A. M., Patch, T. L. and Kaumann, A. J. (1991) The antimigraine drugs ergotaminc and dihydroergotamine are potent 5-HT ${ }_{1 C}$ receptor agonists in piglet choroid plexus. Br. J. Pharmac. 104: 45-48.

Buchheit, K.-H. and Buhl, T. (1991) Prokinetic benzamides stimulate peristaltic activity in the isolated guinea-pig ileum by activation of 5-HT 4 receptors. Eur. J. Pharmac. 205: 203-208.

Burleigh, D. E. and Borman, R. A. (1993) Short-circuit current responses to 5-hydroxytryptamine in human ileal mucosa are mediated by a 5- $\mathrm{HT}_{4}$ receptor. Eur. J. Pharmac. 241: 125-128.

Buzzi, M. G., Moskowitz, M. A., Peroutka, S. J. and Byun, B. (1991) Further characterisation of the putative 5 -HT receptor which mediates blockade of neurogenic plasma extravasation in rat dura mater. $B r . J$. Pharmac. 103: 1421-1428.

Castelao, J. R., Ferreira, L., Gelders, Y. J. and Heylen, S. L. E. (1989) The efficacy of the D-2 and 5-HT antagonist risperidone (R 64766) in psychotic patients. Schizophrenia Res. 2: 411-415.

Chang, J. Y. and Owman, C. (1989) Cerebrovascular serotonergic receptors mediating vasoconstriction: further evidence for the existence of 5-HT2 receptors in rat and 5-HT, - like receptors in guinea-pig basilar arteries. Acta physiol. scand. 136: 59-67.

Charney, D. S., Krystal, J. H., Delgado, P. L. and Heninger, G. R. (1990) Serotonin-specific drugs for anxiety and depressive disorders. Amn. Rev. Med. 41: 437-446.

Chester, A. H., Martin, G. R., Bodelsson, M., Arneklo-Nobin, B., Tadjkarimi, S., Tornebrandt, K. and Yacoub, M. H. (1990) 5-Hydroxytryptamine receptor profile in healthy and diseased human epicardial coronary arteries. Cardiovasc. Res. 24: 932-937.

Chevallier, B. (On behalf of the Granisetron Study Group) (1990) Efficacy and safety of granisetron compared to high-dose metoclopramide plus dexamethasone in patients receiving high-dose cisplatin. Eur. $J$. Cancer 26(Suppl. 1): 33-36.

Clitherow, J. W., Scopes, D. I., Skingle, M., Jordan, C. C., Feniuk, W., Campbell, I. B., Carter, M. C., Collington, E. W., Connor, H. E., Higgins, G. A. and Tyers, M. B. (1994) Evolution of a novel series of [( $N, N$-dimethylamino) propyl]- and piperazinylbenzanilides as the first selective $5-\mathrm{HT}_{\mathrm{ID}}$ antagonists. $J$. med. Chem. 37: 2253-2257.

Connell, L. A. and Wallis, D. I. (1989) 5-Hydroxytryptamine depolarises neonatal rat motoneurones through a receptor unrelated to an identified binding site. Neuropharmacology 28: 625-634.

Connor, H., O'Shaughnessy, C. T., Feniuk, W., Perren, M. J., North, P. C., Oxford, A. W., Butina, D., Owen, M. and Humphrey, P. P. A. (1993) GR85548, a potent selective agonist for the intracranial vascular 5-HT receptor. Br. J. Pharmac. 108: 99P.

Connor, H. E., Feniuk, W., Humphrey, P. P. A. and Perren, M. J. (1986) 5-Carboxamidotryptamine is a selective agonist at 5-hydroxytryptamine receptors mediating vasodilation and tachycardia in anaesthetized cats. $\mathrm{Br}$. J. Pharmac. 87: 417-426.

Connor, H. E., Feniuk, W. and Humphrey, P. P. A. (1989a) 5-Hydroxytryptamine contracts human coronary arteries predominantly via 5-HT 2 receptor activation. Eur. J. Pharmac. 161: 91-94.

Connor, H. E., Feniuk, W. and Humphrey, P. P. A. (1989b) Characterization of 5-HT receptors mediating contraction of canine and primate basilar artery by use of GR43175, a selective 5-HT,-like receptor agonist. Br.J. Pharmac. 96: 379-387.

Corinaldesi, R., Stanghellini, V., Tosetti C., Rea E., Corbelli C., Marengo, M., Monetti, N. and Barbara, L. (1993) The effect of different dosage schedules of cisapride on gastric emptying in idiopathic gastroparesis. Eur. J. clin. Pharmac. 44: 429-432.

Corsi, M., Pietra, C., Toson, G., Trist, D., Tuccitto, G. and Artibani, W. (1991) Pharmacological analysis of 
5-hydroxytryptamine effects on electrically stimulated human isolated urinary bladder. Br. J. Pharmac. 104: $719-725$.

Costall, B., Domeney, A. M., Kelly, M. E. and Naylor, R. J. (1993) New antidementia molecules which selectively influence serotonin receptor subtypes. In: Serotonin, Cell Biology to Pharmacology and Therapeutics, pp. 407-416, Vanhoutte, P. M., Saxena, P. R., Paoletti, R., Brunello, N. and Jackson, A. S. (eds) Kluwer Academic Publishers, Dordrecht.

Costello, N. L., Carlson, J. N., Glick, S. D. and Bryda, M. (1991) The effects of acute administration of gepirone in rats trained on conflict schedules having different degrees of predictability. Pharmac. Biochem. Behav. 40: $795-800$.

Couturier, E. G., Hering, R., Foster, C. A., Steiner, T. J. and Clifford Rose, F. (1991) First clinical study of the selective 5-HT3 antagonist, granisetron (BRL 43694), in the acute treatment of migraine headache. Headache 31: 296-297.

Craig, D. A. and Martin, G. R. (1993) 5-HT H $_{1 \mathrm{~B}}$ receptors mediate potent contractile responses to 5-HT in rat caudal artery. Br. J. Pharmac. 109: 609-611.

Craig, D. A., Eglen, R. M., Walsh, L. K. M., Perkins, L. A., Whiting R. L. and Clarke, D. E. (1990) 5-Methoxytryptamine and 2-methyl-5-hydroxytryptamine-induced desensitisation as a discriminative tool for the $5-\mathrm{HT}_{3}$ and putative 5- $\mathrm{HT}_{4}$ receptors in guinea-pig ileum. Naunyn-Schmiedeberg's Arch. Pharmac. 342: $9-16$.

Curzon, G. and Kennett, G. A. (1990) m-CPP: a tool for studying behavioral responses associated with 5-HT $(1 \mathrm{C})$ receptors. Trends Pharmac. Sci. 11: 181-182.

Dallas, F. A. A., Dixon, C. M., McCulloch, R. J. and Saynor, D. A. (1989) The kinetics of ${ }^{14}$ C-GR43175 in rat and dog. Cephalalgia 9(Suppl. 9): 53-56.

Davies, P. T. G. and Steiner, T. J. (1990) Serotonin $S_{2}$ receptors and migraine: a study with the selective receptor antagonist ICI 169,369. Headache 30: 340-343.

Dhasmana, K. M., Zhu, Y. N., Cruz, S. L. and Villalón, C. M. (1993) Gastrointestinal effects of 5-hydroxytryptamine and related drugs. Life Sci. 53: 1651-1661.

Dogliotti, L., Fagginolo, R., Berrut, A., Antomacci, R. A., Ortega, C. and Lancranjan, J. (1990) Prevention of nausea and vomiting in cisplatin-treated patients by a selective (5-HT $)$ receptor antagonist, ICS $205-930$. Tumori 76: 595-598.

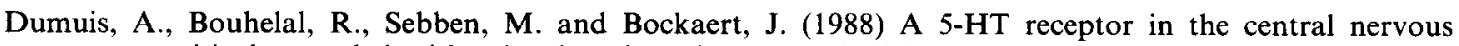
system, positively coupled with adenyl cyclase, is antagonized by ICS 205-930. Eur. J. Pharmac. 146: 187-188.

Dumuis, $\Lambda$., Sebben, M. and Bockaert, J. (1989) The gastrointestinal prokinetic benzamide derivatives are agonists at the non-classical 5 -HT receptor $\left(5-\mathrm{HT}_{4}\right)$ positively coupled to adenylate cyclase in neurons. Naunyn-Schmiedeberg's Arch. Pharmac. 340: 403-410.

Duncker, D. J., Saxena, P. R. and Verdouw, P. D. (1985) 5-Hydroxytryptamine causes tachycardia in pigs by acting on receptors unrelated to 5- $\mathrm{HT}_{1}, 5-\mathrm{HT}_{2}$ or M-type. $\mathrm{Br}$. J. Pharmac. 86: 596P.

Elswood, C. J., Bunce, K. T. and Humphrey, P. P. A. (1991) Identification of putative 5-HT 4 receptors in guinea-pig ascending colon. Eur. J. Pharmac. 196: 149-155.

Engel, G., Göthert, M., Hoyer, D., Schlicker, E. and Hillenbrand, K. (1986) Identity of inhibitory presynaptic 5-hydroxytryptamine (5-HT) autoreceptors in the rat brain cortex with 5-HT ${ }_{\mathrm{LB}}$ binding sites. Naunyn-Schmiedeberg's Arch. Pharmac. 332: 1-7.

Erlander, M. G., Lovenberg, T. W., Baron, B. M., De Lecea, L., Danielson, P. E., Racke, M., Slone, A. L., Siegel, B. W., Foye, P. E., Cannon, K. and Sutcliffe, J. G. (1993) Two members of a distinct subfamily of 5-hydroxytryptamine receptors differentially expressed in rat brain. Proc. natn. Acad. Sci. U.S.A. 90: $3452-3456$.

Erspamer, V. (1954) Pharmacology of indolealkylamines. Pharmac. Rev. 6: 425-487.

Fagni, L., Dumuis, A., Sebben, M. and Bockaert, J. (1992) The 5-HT 4 receptor sub-lype inhibits $\mathrm{K}^{+}$current in colliculi neurones via activation of a cyclic AMP-dependent protein kinase. Br. J. Pharmac. 105: 973-979.

Fargin, A., Raymond, J. R., Lohse, M. J., Kobilka, B. K., Caron, M. G. and Lefkowitz, R. J. (1988) The genomic clone $\mathrm{G}-21$ which resembles a $\beta$-adrenergic receptor sequence encodes the $5-\mathrm{HT}_{1 \mathrm{~A}}$ receptor. Nature 335 : $358-360$.

Feldberg, W. and Toh, C. C. (1953) Distribution of 5-hydroxytryptamine (serotonin, enteramine) in the wall of the digestive tract. J. Physiol. (Lond.) 119: 352-362.

Feniuk, W., Humphrey, P. P. A. and Watts, A. D. (1979) Presynaptic inhibitory action of 5-hydroxytryptamine in dog isolated saphenous vein. Br. J. Pharmac. 67: 247-254.

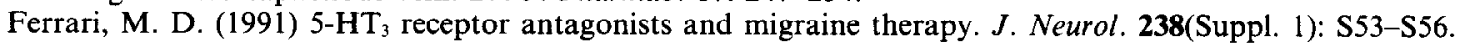

Ferrari, M. D. and Saxena, P. R. (1993) Clinical and experimental effects of sumatriptan in humans. Trends Pharmac. Sci. 14: 129-133.

Ferrari, M. D., Wilkinson, M., Hirt, D., Lataste, X. and Notter, M. (1991) Efficacy of ICS 205-930, a novel 5 -hydroxytryptamine ${ }_{3}\left(5-\mathrm{HT}_{3}\right)$ receptor antagonist, in the prevention of migraine attacks. A complex answer to a simple question. ICS 205-930 Migraine Study Group. Pain 45: 283-291.

Fillion, G. M. B., Rouselle, J.-C., Fillion, M.-P., Beaudoin, D. M., Goiny, M. R., Deniau, J.-M. and Jacob, J. J. (1978) High affinity binding of $\left[{ }^{3} \mathrm{H}\right]$-5-hydroxytryptamine to brain synaptosomal membranes: comparison with $\left[{ }^{3} \mathrm{H}\right]$-lysergic acid diethylamide binding. Molec. Pharmac. 14: 50-59.

Fletcher, A., Bill, D. J., Bill, S. J., Cliffe, I. A., Dover, G. M., Forster, E. A., Haskins, J. T., Jones, D., Mansell, 
H. L. and Reilly, Y. (1993) WAY 100135: a novel, selective antagonist at presynaptic and postsynaptic 5-HT receptors. Eur. J. Pharmac. 237: 283-291.

Foguet, M., Hoyer, D., Pardo, L. A., Parekh, A., Kluxen, F. W., Kalkman, H. O., Stuhmer, W. and Lübbert, H. (1992a) Cloning and functional expression of the rat stomach fundus serotonin receptor. EMBO J. 11: 3481-3487.

Foguet, M., Nguyen, H., Le, H. and Lübbert, H. (1992b) Structure of the mouse 5-HT 1 , 5-HT 2 and stomach fundus serotonin receptor genes. Neuroreport 3: 345-348.

Forbes, I. T., Kennett, G. A., Gadre, A., Ham. P., Hayward, C. J., Martin, R. T., Thompson, M., Wood, M. D., Baxter, G. S. and Glen, A. (1993) $N$-(1-Methyl-5-indoly)- $N^{\prime}$-(3-pyridyl)urea hydrochloride: the first selective 5-HT ${ }_{1 \mathrm{C}}$ receptor antagonist. J. med. Chem. 36: 1104-1107.

Ford, A. P. D. W., Baxter, G. S., Eglen, R. M. and Clarke, D. E. (1992) 5-Hydroxytryptamine stimulates cyclic AMP formation in the tunica muscularis muscosae of the rat oesophagus via 5- $\mathrm{HT}_{4}$ receptors. Eur. $J$. Pharmac. 211: 117-120.

Fozard, J. R. (1990) Agonists and antagonists of 5- $\mathrm{HT}_{3}$ receptors. In: Cardiovascular Pharmacology of 5-Hydroxytryptamine: Prospective Therapeutic Applications, pp. 101-115, Saxena, P. R., Wallis, D. I., Wouters, W. and Bevan, P. (eds) Kluwer Academic Publishers, Dordrecht.

Fozard, J. R. (1992) 5-HT Mechanisms in Primary Headaches, pp. 200-212, Olesen, J. and Saxena, P. R. (eds) Raven Press, New York.

Fozard, J. R. and Gray, J. A. (1989) 5-HT 1 receptor activation: a key step in the initiation of migraine. Trends Pharmac. Sci. 10: 307-309.

Frieling, T., Cooke, H. J. and Wood, J. D. (1991) Serotonin receptors on submucous neurons in guinea pig colon. Am. J. Physiol. 261: G1017-G1023.

Fukui, H., Yamamoto, M., Ando, T., Sasaki, S. and Sato, S. (1993) Increase in serotonin levels in the dog ileum and blood by cisplatin as measured by microdialysis. Neuropharmacology 32: 959-968.

Gaddum, J. H. (1953) Tryptamine receptors. J. Physiol. (Lond.) 119: 363-368.

Gaddum, J. H. and Hameed, K. A. (1954) Drugs which antagonize 5-hydroxytryptamine. Br. J. Pharmac. 9: $240-248$.

Gaddum, J. H. and Picarelli, Z. P. (1957) Two kinds of tryptamine receptors. Br. J. Pharmac. 12: 323-328.

Gaster, L. M., Jennings, A. J., Joiner, G. F., King, F. D., Mulholland, K. R., Rahman, S. K., Starr, S., Wyman, P. A., Wardle, K. A. and Ellis, E. S. (1993) (1-Butyl-4-piperidinyl)methyl-8-amino-7-chloro-1,4-benzodioxane-5-carboxylate hydrochloride: a highly potent and selective $5-\mathrm{HT}_{4}$ receptor antagonist derived from metoclopramide. J. med. Chem. 36: 4121-4123.

Geldof, H., Hazelhoff, B. and Otten, M. H. (1993) Two different dose regimens of cisapride in the treatment of reflux oesophagitis: a double-blind comparison with ranitidine. Aliment. Pharmac. Ther. 7: 409-415.

Gerald, C., Adham, N., Kao, H. T., Schechter, L. E., Olsen, M. A., Bard, J. A., Laz, T. M., Vaysse, P. J. J., Branchek, T. A. and Weinshank, R. L. (1994) The 5-HT ${ }_{4}$ receptor: molecular cloning of two splice variants. In: Abstracts Book, Third IUPHAR Satellite Symposium on Serotonin, Chicago, p. 82.

Gershon, M. D., Wade, P. R., Fiorica-Howells, E., Kirchgessner, A. L. and Tamir, H. (1991) 5-HT ${ }_{1 P}$ receptors in the bowel: G-protein coupling, localisation and function. In: Serotonin: Biology, Receptors and Functional Effects, pp. 133-143, Fozard, J. R. and Saxena, P. R. (eds) Birkhauser Verlag, Basel.

Glasser, T. (1988) Ipsapirone, a potent and selective 5- $\mathrm{HT}_{1 \mathrm{~A}}$ receptor ligand with anxiolytic and antidepressant properties. Drugs Future 13: 429-439.

Glennon, R. A., Naiman, N. A., Pierson, M. E., Titeler, M., Lyon, R. A. and Weisberg, E. (1988) NAN-190, an arylpiperazine analog that antagonises the stimulus effects of the 5-HT $\mathrm{HA}_{1 \mathrm{~A}}$ agonist 8-hydroxy-2-di-npropylaminotetralin. Eur. J. Pharmac. 154: 339-342.

Glusa, E. (1992) Evidence for 5-HT 1 c receptor-mediated endothelium-dependent relaxation of porcine pulmonary arteries invitro. In: 5-Hydroxytryptamine Mechanisms in Primary Headaches, pp. 168-172, Olesen, J. and Saxena, P. R. (eds) Raven Press, New York.

Glusa, E. and Müller-Schweinitzer, E. (1993) Heterogeneity of 5-HT receptor subtypes in isolated human femoral and saphenous veins. Naunyn-Schmiedeberg's Arch. Pharmac. 347: 133-136.

Goa, K. L. and Ward, A. (1986) Buspirone, a preliminary review of its pharmacological properties and therapeutic efficacy as an anxiolytic. Drugs 32: 114-129.

Goldberg, H. L. and Finnerty, R. J. (1979) The comparative efficacy of buspirone and diazepam in the treatment of anxiety. Am. J. Psychiat. 136: 1184-1187.

Gore, S., Gilmore, I. T., Haigh, C. G., Brownless, S. M., Stockdale, H. and Morris, A. I. (1990) Colonic transil in man is slowed by ondansetron (GR 38032F), a selective 5-hydroxytryptamine receptor (type 3) antagonist. Aliment. Pharmac. Ther. 4: 139-144.

Göthert, M. and Kolassa, N. (1990) 5-HT 1 IA receptors in the brain and blood pressure. J. curdiovasc. Pharmac. 16(Suppl. 7): S1-S91.

Göthert, M., Schilker, E. and Kollecker, P. (1986) Receptor-mediated effects of serotonin and 5 -methoxytryptamine on noradrenaline release in the rat vena cava and in the heart of the pithed rat. Naunyn-Schmiedeberg's Arch. Pharmac. 332: 124-130.

Gralla, R. J., Hari, L. M., Pisko, S. E., Squillante, A. E., Kelson, D. P., Braun, D. W., Bordin, L. A., Braun, T. J. and Young, C. W. (1981) Antiemetic efficacy of high dose metoclopramide: randomized trial with placebo 
and prochlorperazine in patients with chemotherapy induced nausea and vomiting. N. Engl.J.Med. 305: 905-909.

Greenshaw, A. J. (1993) Behavioral pharmacology of 5-HT receptor antagonists: a critical update on therapeutic potential. Trends Pharmac. Sci. 14: 265-270.

Grossman, C. J., Kilpatrick, G. J. and Bunce, K. T. (1993) Development of a radioligand binding assay for 5- $\mathrm{HT}_{4}$ receptors in guinea-pig and rat brain. Br. J. Pharmac. 109: 618-624.

Grunberg, S. M., Groshen, S., Robinson, D. C., Stevenson, L. L. and Sanderson, P. E. (1990) Correlation of anti-emetic efficacy and plasma levels of ondansetron. Eur. J. Cancer 26: 879-882.

Gudermann, T., Levy, F. O., Birnbaumer, M., Birnbaumer, L. and Kaumann, A. J. (1993) Human S31 serotonin receptor clone encodes a 5-hydroxytryptamine $\mathrm{iE}_{\mathrm{E}}$-like serotonin receptor. Molec. Pharmac. 43: $412-418$.

Gullikson, G. W., Virina, M. A., I oeffler, R. F., Yang, D. C., Goldstin, B., Wang, S. X., Moummi, C., Flynn, D. L. and Zabrowski, D. L. (1993) SC-49518 enhances gastric emptying of solid and liquid meals and stimulates gastrointestinal motility in dogs by a 5-hydroxytryptamine ${ }_{4}$ receptor mechanism. $J$. Pharmac. exp. Ther. 264: 240-248.

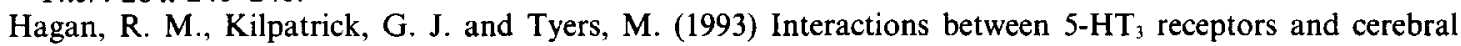
dopamine function: implications for the treatment of schizophrenia and psychoactive substance abuse. Psychopharmacology 112(Suppl. 1): S68-S75.

Hamblin, M. W. and Metcalf, M. A. (1991) Primary structure and functional characterisation of a human 5-HT ID $_{\text {D }}$ type serotonin receptor. Molec. Pharmac. 40: 143-148.

Hamblin, M. W., McGuffin, R. W., Metcalf, M. A., Dorsa, D. M. and Merchan, K. M. (1992) Distinct 5-HT 1 and 5-HT $1 \mathrm{D}$ serotonin receptors in rat: structural and pharmacological comparison of the two cloned receptors. Molec. Cell. Neurosci. 3: 578-587.

Hamel, E. and Bouchard, D. (1991) Contractile 5-HT receptors in human isolated pial arterioles: correlation with 5-HT $\mathrm{H}_{1 \mathrm{D}}$ binding sites. Br. J. Pharmac. 102: 227-233.

Hamel, E, Fan, E., Linville, D., Ting, V., Villemure, J.-G. and Chia, L.-S. (1993) Expression of mRNA for serotonin 5-hydroxytryptamine ${ }_{1 \mathrm{D} \beta}$ receptor subtype in human and bovine cerebral arteries. Molec. Pharmac. 44: $242-246$.

Hamon, M., Gallissot, M. C., Menard, F., Gozlan, H., Bourgoin, S. and Verge, D. (1989) 5-HT 3 receptor binding sites are on capsaicin-sensitive fibres in the rat spinal cord. Eur. J. Pharmac. 164: 315-322.

Harpel-Dupas, C., Cloez, I. and Fillion, G. (1991) The inhibitory effect of trifluoromethylphenylpiperazine on [ $\left.{ }^{3} \mathrm{H}\right]$ acetylcholine release in guinea pig hippocampal synaptosomes is mediated by a

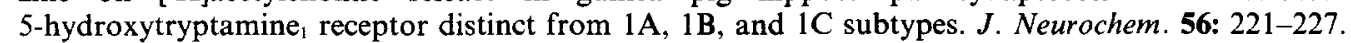

Hartig, P. R., Branchek, T. A. and Weinshank, R. L. (1992) A subfamily of 5-HT ${ }_{10}$ receptor genes. Trends Pharmac. Sci. 13: 152-159.

Heninger, G. R., Charney, D. S. and Smith, A. (1987) Effects of serotonin receptor agonists and antagonists on neuroendocrine function in rhesus monkeys. Soc. Neurosci. Abstr. 13: 801.

Heuring, R. E. and Peroutka, S. J. (1987) Characterization of a novel $\left[{ }^{3} \mathrm{H}\right] 5$-hydroxytryptamine binding site subtypc in bovine brain membranes. J. Ncurosci. 7: 894903.

Hoyer, D., Pazos, A., Probst, A. and Palacios, J. M. (1986) Serotonin receptors in the human brain I. Characterisation and autoradiographic localisation of 5-HT $1 \mathrm{~A}$ recognition sites. Apparent absence of 5-HT recognition sites. Brain Res. 376: 8596.

Hoyer, D., Boddeke, H. and Schoeffter, P. (1991) Second messengers in the definition of 5-HT receptors. In: Serotonin: Molecular Biology, Receptors and Functional Effects, pp. 117-132, Fozard, J. R. and Saxena, P. R. (eds) Birkhauser, Basel.

Hoyer, D., Clarke, D. E., Fozard, J. R., Hartig, P. R., Martin G. R., Mylecharane, E. J., Saxena, P. R. and Humphrey, P. P. A. (1994) The IUPHAR classification of receptors of 5-hydroxytryptamine (serotonin). Pharmac. Rev. 46: 157-203.

Humphrey, P. P. A. (1983) Pharmacological characterization of cardiovascular 5-hydroxytryptamine receptors. In: Vascular Neuroeffector Mechanism, Fourth International Symposium, pp. 237-243, Bevan, J. A., Fujiwara, M., Maxwell, R. A., Mohri, K., Shibata, S. and Toda, N. (cds) Macmillan, London.

Humphrey, P. P. A. and Feniuk, W. (1987) Pharmacological characterisation of functional neuronal receptors for 5-hydroxytryptamine. In: Neuronal Messengers in Vascular Function, pp. 3-19, Nobin, A., Owman, C. and Arneklo-Nobin, B. (eds) Elsevier Science, Amsterdam.

Humphrey, P. P. A. and Feniuk, W. (1991) Mode of action of the anti-migraine drug sumatriptan. Trends Pharmac. Sci. 12: 444 446.

Humphrey, P. P. A., Hartig, P. and Hoyer, D. (1993) A proposed new nomenclature for 5-HT receptors. Trends Pharmac. Sci. 14: 233-236.

Imaizumi, Y., Baba, M. and Watanabe, M. (1984) Involvement of endothelium in the relaxation of isolated chick jugular vein by 5-hydroxytryptaminc. Eur. J. Pharmac. 97: 335-336.

Jahnel, U., Rupp, J., Ert1, R. and Nawrath, H. (1992) Positive inotropic response to 5-HT in human atrial but not in ventricular heart muscle. Naunyn-Schmiedeberg's Arch. Pharmac. 346: 482-485.

Jin, H., Oksenberg, D., Askenazi, A., Peroutka, S. J., Duncan, A. M. V., Rozmahel, R., Yang, Y, Mengod, G., Palacios, J. M. and O'Dowd, B. F. (1992) Characterisation of the human 5-hydroxytryptamine ${ }_{1 \mathrm{~B}}$ receptor. J. biol. Chem. 267: 5735-5738.

Johnson, M. R. and North, P. C. (1993) Indole derivatives. Glaxo Group Ltd. Patent No. WO9314087. 
Julius, D., MacDermott, A. B., Axel, R. and Jessel, T. M. (1988) Molecular characterisation of a functional cDNA encoding the serotonin ${ }_{1 C}$ receptor. Science 214: 558-564.

Julius, D., Huang, K. N., Livelli, T. J., Axel, R. and Jessell, T. M. (1990) The 5-HT, receptor defines a family of structurally distinct but functionally conserved serotonin receptors. Proc. natn. Acad. Sci. U.S.A. 87: 928-932.

Kaumann, A. J. (1990) Piglet sinoatrial 5-HT receptors resemble human atrial 5-HT 4 -like receptors. Naunyn-Schmiedeberg's Arch. Pharmac. 342: 619-622.

Kaumann, A. J. and Sanders, L. (1994) 5-Hydroxytryptamine causes rate-dependent arrhythmias through 5-HT $\mathrm{H}_{4}$ receptors in human atrium: facilitation by chronic beta-adrenoceptor blockade. Naunyn-Schmiedeberg's Arch. Pharmac. 349: 331-337.

Kaumann, A. J., Sanders, L., Brown, A. M., Murray, K. J. and Brown, M. J. (1990) A 5-hydroxytryptamine receptor in human atrium. Br.J. Pharmac. 100: 879-885.

Kaumann, A. J., Saunders, K., Brown, A. M., Murray, K. J. and Brown, M. J. (1991) A 5-HT 4 -like receptor in human right atrium. Naunyn-Schmiedeberg's Arch. Pharmac. 344: 150-159.

Kawagishi, T., Nishizawa, Y., Okuno, Y., Sekiya, K. and Morii, H. (1993) Effect of cisapride on gastric emptying of indigestible solids and plasma motilin concentration in diabetic autonomic neuropathy. Am. J. Gastroenterol. 88: 933-938.

Kenakin, T. P., Bond, R. A. and Bonner, T. I. (1992) Definition of pharmacological receptors. Pharmac. Rev. 44: $351-362$.

Kennett, G. A. (1993) 5-HT ${ }_{\mathrm{IC}}$ receptors and their therapeutic relevance. Curr. Drugs: Serotonin April: $125-170$.

Kilpatrick, G. J., Jones, B. J. and Tyers, M. B. (1987) The identification and distribution of 5-HT 3 receptors in rat brain using radioligand binding. Nature 330: 746-748.

Kilpatrick, G. J., Butler, A., Hagan, R. M., Jones, B. J. and Tycrs, M. B. (1990) [ ${ }^{3}$ H]GR67330, a very high affinity ligand for 5- $\mathrm{HT}_{3}$ receptors. Naunyn-Schmiedeberg's Arch. Pharmac. 342: 22-30.

King, F. D., Gaster, L. M., Kaumann, A. J. and Young, R. C. (1993a) Use of tetrahydrocarbazone derivatives as $5-\mathrm{HT}_{1}$ receptor agonists. SmithKline Beecham plc. Patent No. WO9300086.

King, F. D., Hadley, M. S., Joiner, K. T., Martin, R. T., Sanger, G. J., Smith, D. M., Smith, G. E., Smith, P., Turner, D. H. and Watts, E. A. (1993b) Substituted benzamides with conformationally restricted side chains. 5. Azabicyclo[x.y.z] derivatives as $5-\mathrm{HT}_{4}$ receptor agonists and gastric motility stimulants. $J$. med. Chem. 36: 683-689.

Kobilka, B. K., Frielle, T., Collins, S., Yang-Feng, T., Kobilka, T. S., Francke, U., Lefkowitz, R. J. and Caron, C. G. (1987) An intronless gene encoding a potential member of the family of receptors coupled to guanine nucleotide regulatory proteins. Nature 329: 75-77.

Koe, B. K., Lebel, L. A., Fox, C. B. and Macor, J. E. (1992) Characterisation of [ $\left.{ }^{3} \mathrm{H}\right]$ CP-96,501 as a selective radioligand for the serotonin 5- $\mathrm{HT}_{1 \mathrm{~B}}$ receptor: binding studies in rat brain membranes. $J$. Neurochem. 58: $1268-1276$

Kolassa, N., Beller, K. D., Boer, R., Boss, H. and Sanders, K. H. (1993) Urapidil: the role of 5-HT ${ }_{1 A}$ and $\alpha$-adrenergic receptors in blood pressure reduction. In: Serotonin, Cell Biology to Pharmacology and Therapeutics, pp. 151-157, Vanhoutte, P. M., Saxena, P. R., Paoletti, R., Brunello, N. and Jackson, A. S. (eds) Kluwer, Dordrecht.

Kursar, J. D., Nelson, D. L., Wainscott, D. B., Cohen, M. L. and Baez, M. (1992) Molecular cloning, functional expression and pharmacological characterisation of a novel serotonin receptor (5-hydroxytryptamine ${ }_{2 F}$ ) from rat stomach fundus. Molec. Pharmac. 42: 549-557.

Laporte, A. M., Kidd, E. J., Verge, D., Gozlan, H. and Hamon, M. (1992) Autoradiographic mapping of central

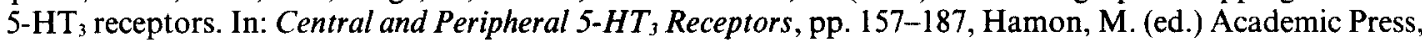
London.

Lefebvre, H., Contesse, V., Delarue, C., Soubrane, C., Legrand, A., Kuhn, J. M., Wolf, L. M. and Vaudry, H. (1993) Effect of the serotonin ${ }_{4}$ receptor agonist zacopride on aldosterone secretion from the human adrenal cortex: in vivo and in vitro studies. J. clin. Endocrin. Metab. 77: 1662-1666.

Leff, P., Martin, G. R. and Morse, J. M. (1987) Differential classification of vascular smooth muscle and endothelial cell 5-HT receptors by use of tryptamine analogues. Br. J. Pharmac. 91: 321-331.

Leonhardt, S., Herrick-Davies, K. and Titeler, M. (1989) Detection of a novel serotonin receptor subtype $\left(5-\mathrm{HT}_{1 \mathrm{E}}\right)$ in human brain: interaction with a GTP-binding protein. $J$. Neurochem. 53: 465-471.

Levy, F. O., Gudermann, T., Birnbaumer, M., Kaumann, A. J. and Birnbaumer, L. (1992a) Molecular cloning of a human gene (S31) encoding a novel serotonin receptor mediating inhibition of adenylyl cyclase. FEBS Lett. 296: 201-206.

Levy, F. O., Gudermann, T., Peres-Reyes, E., Birnbaumer, M., Kaumann, A. J. and Birnbaumer, L. (1992b) Molecular cloning of a human serotonin receptor (S12) with a pharmacological profile resembling that of the 5-HT ${ }_{\text {ID }}$ subtype. J. biol. Chem. 267: 7553-7562.

Limberger, N., Deicher, R. and Starke, K. (1991) Species differences in presynaptic serotonin autoreceptors: mainly $5-\mathrm{HT}_{1 \mathrm{~B}}$ but possibly in addition $5-\mathrm{HT}_{1 \mathrm{D}}$ in the rat, $5-\mathrm{HT}_{\mathrm{ID}}$ in the rabbit and guinea-pig brain cortex. Naunyn-Schmiedeberg's Arch. Pharmac. 343: 353-364.

Loisy, C., Beorchia, S., Centzone, V., Fozard, J. R., Schechter, P. J. and Tell, G. P. (1985) Effects on migraine headache of MDL 7222, an antagonist at neuronal 5-HT receptors. Double-blind, placebo-controlled study. Cephalalgia 5: 79-82. 
Loric, S., Launay, J. M., Colas, J. F. and Maroteaux, L. (1992) New mouse 5-HT,-like receptor. Expression in brain, heart and intestine. FEBS Lett. 312: 203-207.

Lovenberg, T. W., Baron, B. M., De Lecea, L., Miller J. D., Prosser, R. A., Rea, M. A., Foye, P. E., Racke, M., Slone, A. L., Siegel, B. W., Erlander, M. G., Danielson, P. E. and Sutcliffe, J. G. (1993a) A novel adenylyl cyclase-activating serotonin receptor $\left(5-\mathrm{HT}_{7}\right)$ implicated in the regulation of mammalian circadian rhythms. Neuron 11: 449-458.

Lovenberg, T. W., Erlander, M. G., Baron, M. G., Racke, M., Slone, A. L., Siegel, B. W., Craft, C. M., Burns, J.

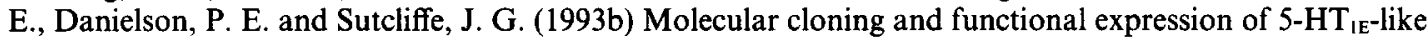
rat and human 5-hydroxytryptamine receptor genes. Proc. natn. Acad. Sci. U.S.A. 90: 2184-2188.

Lübbert, H., Hoffman, B. J., Snutch, T. P., Vandyke, T., Levine, A. J., Hartig, P. R., Lester, H. A. and Davidson, N. (1987a) cDNA cloning of a serotonin 5-HT ${ }_{1 C}$ receptor by electrophysiological assays of mRNA-injected Xenopus oocytes. Proc. natn. Acad. Sci. U.S.A. 84: 4322-4336.

Lübbert, H., Snutch, T. P., Dascal, N., Lester, H. A. and Davidson, N. (1987b) Rat brain 5-HT $1 \mathrm{C}$ receptors are encoded by a 5-6 kbase mRNA size class and are functionally expressed in injected Xenopus oocytes. $J$. Neurosci. 7: 1159-1165.

Lucki, I. (1992) 5-HT, receptors and behaviour. Neurosci. Behav. Rev. 16: 83-93.

Ludwig, C. and Schmidt, A. (1868) Das Verhalten der Gase, welche mit dem Blut durch den reizbaren Säugethiermuskel strömen. Arb. a. d. Physiol. Anstalt z. Leipzig 3: 1.

Maricq, A. V., Peterson, A. S., Brake, A. J., Myers, R. M. and Julius, D. (1991) Primary structure and functional expression of the 5- $\mathrm{HT}_{3}$ receptor, a serotonin-gated ion channel. Science 254: 432-437.

Maroteaux, K., Saudou, F., Amlaiky, N., Boschert, U., Plassat, J. L. and Hen, R. (1992) The mouse 5-HT 1 B serotonin receptor: cloning, functional expression and localisation in motor control centres. Proc. natn. Acad. Sci. U.S.A. 89: 3020-3024.

Martin, G. R. and MacLennan, S. J. (1990) Analysis of the receptor in rabbit saphenous vein exemplifies the problems of using exclusion criteria for receptor classification. Naunyn-Schmiedeberg's Arch. Pharmac. 342: $111-119$.

Martin, G. R., Leff, P., Cambridge, D. and Barrett, V. J. (1987) Comparative analysis of two types of 5-hydroxytryptamine receptor mediating vasorelaxation: differential classification using tryptamines. Naunyn-Schmiedeberg's Arch. Pharmac. 336: 365-373.

Martin, G. R., Browning, C. and Giles, H. (1993) Further characterisation of an atypical 5-HT receptor mediating endothelium-dependent vasorelaxation. Br. J. Pharmac. 110: 137P.

Marty, M., Pouillart, P., School, S., Droz, J. P., Azab, M., Brion, N., Pujade-Lauraine, E., Paule, B., Paes, D. and Bons, J. (1990) Comparison of the 5-hydroxytryptamine 3 (serotonin) antagonist ondansetron (GR 38032F) with high dose metoclopramide in the control of cisplatin-induced emesis. N. Engl. J. Med. 322: $816-821$.

Matsubara, T., Moskowitz, M. A. and Byun, B. (1991) CP-93,129, a potent and selective 5-HT IB $_{\text {receptor agonist }}$ blocks neurogenic plasma extravasation within rat but not guinea-pig dura mater. Br. J. Pharmac. $104: 3-4$.

Matthes, H., Boschert, U., Amlaiky N., Grailhe, R., Plassat, J. L., Muscatelli, F., Mattei, M. G. and Hen, R. (1993) Mouse 5-hydroxytryptamine ${ }_{S A}$ and 5-hydroxytryptamine ${ }_{S B}$ receptors define a new family of serotonin receptors: cloning, functional expression, and chromosomal localization. Molec. Pharmac. 43: 313-319.

McAllister, G., Charlesworth, A., Snodin, C., Beer, M. S., Noble, A. J., Middlemiss, D. N., Iversen, L. L. and

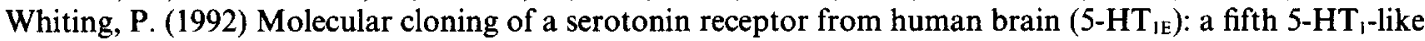
sub-type. Proc. natn. Acad. Sci. U.S.A. 89: 5517-5521.

McDonald, I. A., Dudlcy, M. W., Bcrnotas, R. C. and Sprouse, J. S. (1992) Serotonin 5-HT 1 and 5-HT antagonists. Merrel Dow Pharmaceuticals Inc. Patent No. EP-478954.

McGourty, J. C., Silas, J. H. and Cowan, K. J. (1985) Controlled trial of ketanserin in hypertension. Br. J. clin. Pharmac. 20: $37-40$.

McKernan, R. M., Biggs, C. S., Gillard, N., Quirk, K. and Ragan, C. R. (1990) Molecular size of the 5-HT 3 receptor solubilised from NCB 20 cells. Biochem. J. 269: 623-628.

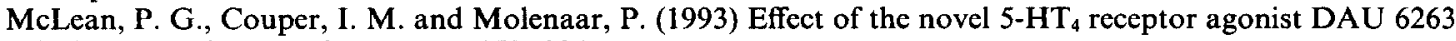
in human colon. Med. J. Austr. 159: 834.

Mellor, S. T., Lewis, S. J., Brody, M. J. and Gebhart, G. E. (1991) The peripheral nociceptive actions of intravenously administered 5-HT in the rat requires dual activation of both $5-\mathrm{HT}_{2}$ and $5-\mathrm{HT}_{3}$ receptor subtypes. Brain Res. 561: 61-68.

Meyerhof, W., Obermuller, F., Fehr, S. and Richter, D. (1993) A novel rat serotonin receptor: primary structure, pharmacology and expression pattern in distinct brain regions. DNA Cell Biol. 12: 401-409.

Middlemiss, D. N. (1986) Blockade of the central 5-HT autoreceptor by $\beta$-adrenoceptor antagonists. Eur. $J$. Pharmac. 120: 51-54.

Middlemiss, D. N. and Fozard, J. R. (1983) 8-Hydroxy-2-(di-n-propylamino) tetralin discriminates between

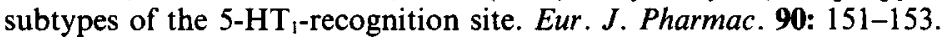

Miller, K. J. and Teitler, M. (1992) Quantitative autoradiography of 5-CT sensitive (5-HT 10 ) and 5-CT insensitive (5-HT $\mathrm{HE}_{1 \mathrm{E}}$ ) scrotonin receptors in human brain. Neurosci. Lett. 136: 223-226.

Min, S. K., Rhee, C. S., Kim, C. E. and Kang, D. Y. (1993) Risperidone versus haloperidol in the treatment of chronic schizophrenic patients: a parallel group double-blind comparative trial. Yonsei Med. J. 34: $179-190$. 
Miner, W. D. and Sanger, C. J. (1986) Inhibition of cisplatin-induced vomiting by 5-hydroxytryptamine M-receptor antagonism. Br. J. Pharmac. 88: 497-499.

Molderings, G. J., Göthert, M., Fink, K., Roth, E. and Schlicker, E. (1989) Inhibition of noradrenaline release in the pig coronary artery via a novel serotonin receptor. Eur. J. Pharmac. 164: 213-222.

Molderings, G. J., Werner, K., Likungu, J. and Göthert, M. (1990) Inhibition of noradrenaline release from the sympathetic nerves of the human saphenous vein via presynaptic 5-HT receptor similar to the 5-HT subtype. Naunyn-Schmiedeberg's Arch. Pharmac. 342: 371-377.

Monsma, F. J., Jr, Shen, Y., Ward, R. P., Hamblin, M. W. and Sibley, D. R. (1993) Cloning and expression of a novel serotonin receptor with high affinity for tricyclic psychotropic drugs. Molec. Pharmac. 43: 320-327.

Moskowitz, M. A. (1992) Neurogenic versus vascular mechanisms of action of sumatriptan and ergot alkaloids in migraine. Trends Pharmac. Sci. 13: 307-311.

Müller-Schweinitzer, E. (1990) Venoconstrictor responses to dihydroergocristine and dihydroergotamine: evidence for the involvement of 5-HT 1 -like receptors. Cardiovasc. Drugs Ther. 4: 1455-1460.

Mundey, M. K., Fletcher, A. and Marsden, C. A. (1994) Effect of the putative 5-HT1A antagonists WAY100135 and SDZ 216-525 on 5-HT neuronal firing in the guinea-pig dorsal raphe nucleus. Neuropharmacology 33: $61-66$.

Murphy, D. L., Broocks, A., Aulakh, C. and Pigott, T. A. (1993) Anxiolytic effects of drugs acting on 5-HT receptor subtypes. In: Serotonin, Cell Biology to Pharmacology and Therapeutics, pp. 223-230, Vanhoutte, P. M., Saxena, P. R., Paoletti, R., Brunello, N. and Jackson, A. S. (eds) Kluwer, Dordrecht.

North, R. A. and Uchimura, N. (1989) 5-Hydroxytryptamine acts at 5-HT 2 receptors to decrease potassium conductance in rat nucleus accumbens neurones. $J$. Physiol. (Lond.) 417: 1-12.

Orwin, J. M. and Fozard, J. R. (1986) Blockade of the flare response to intradermal S-hydroxytryptamine in man by MDL 72222, a selective antagonist at neuronal 5-hydroxytryptamine receptors. Eur. J. clin. Pharmac. 30: 209212.

Oxford, A. W. (1993) Substituted phenylcarbamates and phenylureas, their preparation and use as 5-HT antagonists. Glaxo Group Limited Patent No. WO9320071.

Page, I. H. (1958) Serotonin (5-hydroxytryptamine). Physiol. Rev. 34: 563-588.

Page, I. H. and McCubbin, J. W. (1953) Modification of vascular responses to serotonin. Am. J. Physiol. (Lond.) 174: $436-440$.

Pazos, A., Hoyer, D. and Palacios, J. M. (1984) The binding of serotonergic ligands to the porcine choroid plexus: characterization of a new type of serotonin recognition site. Eur. J. Pharmac. 106: 539-546.

Pazos, A., Probst, A. and Palacios, J. M. (1987) Serotonin receptors in the human brain. III. Autoradiographic mapping of serotonin-2 receptors. Neuroscience 21: 123-139.

Parsons, A. A., Whalley, E. T., Feniuk, W., Connor, H. and Humphrey, P. P. A. (1989) 5-HT,-like receptors mediate 5-hydroxytryptamine-induced contraction of human isolated basilar artery. Br. J. Pharmac. 96: 434-440.

Pecknold, J. C., Luthe, L., Scott Fleury, M. H. and Jenkins, S. (1993) Gepirone and the treatment of panic disorder: an open study. J. clin. Psychopharmac. 13: 145-149.

Pedigo, B. W., Yamamura, II. I. and Nelson, D. L. (1981) Discrimination of multiple serotonin binding sites by the neuroleptic spiperone in rat brain. J. Neurochem. 36: 220-226.

Peroutka, S. J. and Snyder, S. H. (1979) Multiple serotonin receptors: differential binding of [ $\left.{ }^{3} \mathrm{H}\right]$-5-hydroxytryptamine, [ $\left.{ }^{3} \mathrm{I}\right]$-lysergic acid diethylamide and $\left[{ }^{3} \mathrm{H}\right]$-spiroperidol. Molec. Pharmac. 16: $687-699$.

Perren, M. J., Connor, H., Feniuk, W., North, P. C., Saynor, D. A. and Humphrey, P. P. A. (1993) Pharmacological activity in vivo of GR85548, a selective 5-HT receptor agonist. Br. J. Pharmac. 108: $260 \mathrm{P}$.

Plassat, J. L., Boschert, U., Amlaiky, N. and Hen, R. (1992) The mouse 5-HT 5 receptor reveals a remarkable heterogeneity within the 5-HT 1 receptor family. EMBO J. 11: 4779-4786.

Plassat, J. L., Amlaiky, N. and Hen, R. (1993) Molecular cloning of a mammalian serotonin receptor that activates adenylyl cyclase. Molec. Pharmac. 44: 229-236.

Preston, G. C., Millson, D. S., Ceuppens, P. R. and Warburton, D. M. (1992) Effects of the 5-HT receptor $^{-}$ antagonist GR-68755 on a scopolamine-induced cognitive deficit in healthy subjects. Br. J. clin. Pharmac. 33: 546.

Prior, A. and Read, N. W. (1993) Reduction of rectal sensitivity and post-prandial motility by granisetron, a $5-\mathrm{HT}_{3}$-receptor antagonist, in patients with irritable bowel syndrome. Aliment. Pharmac. Ther. 7: 175-180.

Pritchett, D. B., Bach, A. W. J., Wozny, M., Taleb, O., Dal Toso, R., Shih, J. C. and Seeburg, P. H. (1988) Structure and functional expression of cloned rat serotonin 5-HT2 receptor. EMBO J. 7: 4135-4140.

Radja, F., Laporte, A. M., Daval, G., Verge, D., Gozlan, H. and Hamon, M. (1991) Autoradiography of serotonin receptor subtypes in the central nervous system. Neurochem. Int. 18: 1-15.

Ramage, A. G. (1986) A comparison of the effects of doxazosin and alfuzosin with those of urapidil on preganglionic sympathetic nerve activity in anaesthetized cats. Eur. J. Pharmac. 129: 307-314.

Rapport, M. M. (1949) Serum vasoconstrictor (serotonin). V. The presence of creatinine in the complex: a proposed study of the vasoconstrictor principle. J. biol. Chem. 180: 961-969.

Rapport, M. M. and Koelle, G. B. (1953) The action of antihistamines and atropine in blocking the spasmogenic activity of serotonin on the guinea pig ileum. Arch. int. Pharmacodyn. Ther. 92: 464-470. 
Rapport, M. M., Green A. A. and Page, I. H. (1948) Serum vasoconstrictor (serotonin). IV. Isolation and characterization. J. biol. Chem. 176: 1243-1251.

Reeves, J. J., Bunce, K. T. and Humphrey, P. P. A. (1991) Investigation into the 5-hydroxytryptamine receptor mediating smooth muscle relaxation in rat oesophagus. Br. J. Pharmac. 103: 1067-1072.

Richardson, B. P., Engel, G., Donatsch, P. and Stadler, P. A. (1985) Identification of serotonin M receptor subtypes and their specific blockade by a new class of drugs. Nature 316: 126-131.

Robertson, A. D., Hill, A. P., Glen, R. C. and Martin, G. R. (1991) Therapeutic heterocyclic compounds. Wellcome Foundation Patent No. WO9118897.

Rocha, E., Silva, M., Valle, I. R. and Picarelli, Z. P. (1953) A pharmacological analysis of the mode of action of serotonin (5-hydroxytryptamine) upon the guinea-pig ileum. Br. J. Pharmac. 8: 378-388.

Ruat, M., Traiffort, E., Arrang, J. M., Tardivel-Lacombe, J., Diaz, J., Leurs, R. and Schwartz, J. C. (1993a) A novel rat serotonin (5-HT $)$ receptor: molecular cloning, localization and stimulation of cAMP accumulation. Biochem. biophys. Res. Commun. 193: 268-276.

Ruat, M., Traiffort, E., Leurs, R., Tardivel-Lacombe, J., Diaz, J., Arrang, J. M. and Schwartz, J. C. (1993b) Molecular cloning, characterization and localization of a high-affinity serotonin receptor (5-HT H $_{7}$ activating cAMP formation. Proc. natn. Acad. Sci. U.S.A. 90: 8547-8551.

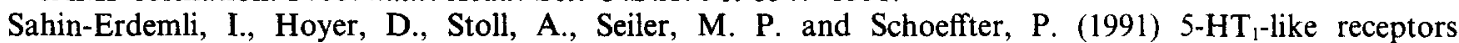
mediate 5-hydroxytryptamine-induced contraction of guinea-pig isolated iliac artery. $B r . J$. Pharmac. 102: 386-390.

Saito, K., Moskowitz, S. and Moskowitz, M. A. (1988) Ergot alkaloids block neurogenic extravasation in dura mater. Proposed action in vascular headache. Ann. Neurol. 24: 732-737.

Saltzmann, A. G., Morse, B., Whitman, M. M., Ivanschchenko, Y., Jaye, M. and Felder, S. (1991) Cloning of the human serotonin 5-HT $\mathrm{HT}_{2}$ and $5-\mathrm{HT}_{1 \mathrm{C}}$ receptor subtypes. Biochem. biophys. Res. Commun. 181: 1469-1478.

Saxena, P. R. (1970) Ganglion-blocking, neuromuscular-blocking and other actions of 2-imino-4-ethyloxycarbonyl-1,3-diaza-cycloheptane hydrochloride (OG 30), a ganglionic stimulant. Eur. J. Pharmac. 11: 75-83.

Saxena, P. R. (1972) The effects of antimigraine drugs on the vascular responses evoked by 5-hydroxytryptamine and related biogenic substances on the external carotid bed of dogs: possible pharmacological implications to their antimigraine action. Headache 12: 44-54.

Saxena, P. R. (1986) Nature of the 5-hydroxytryptamine receptors in mammalian heart. Prog. Pharmac. 6: $173-185$.

Saxena, P. R. and Den Boer, M. O. (1991) Pharmacology of antimigraine drugs. J. Neurol. 238(Suppl. 1): S28-S35.

Saxena, P. R. and De Vlaam-Schluter, G. M. (1974) Role of some biogenic substances in migraine and relevant mechanism in antimigraine action of ergotamine. Studies in an animal experimental model for migraine. Headache 13: 142-163.

Saxena, P. R. and Ferrari, M. D. (1989) 5-HT - -like receptor agonists and the pathophysiology of migraine. Trends Pharmac. Sci. 10: 200-204.

Saxena, P. R. and Tfelt-Hansen, P. (1993) Sumatriptan. In: The Headache, pp. 329-341, Olesen, J., Tfelt-Hansen, P. and Welch, K. M. A. (eds) Raven Press, New York.

Saxena, P. R. and Villalón, C. M. (1990a) Cardiovascular effects of serotonin agonists and antagonists. J. Cardiovasc. Pharmac. 15(Suppl. 7): S17-S34.

Saxena, P. R. and Villalón, C. M. (1990b) Brain 5-HT $\mathrm{HA}_{1 \mathrm{~A}}$ receptor agonism: a novel mechanism for antihypertensive action. Trends Pharmac. Sci. 11: 95-96.

Saxena, P. R. and Wouters, W. (1990) Interferences with 5-hydroxytryptamine. In: Pharmacology of Antihypertensive Therapeutics, Handbook of Pharmacology. Vol. 93, pp. 533-558, Ganten, D. and Mulrow, P. J. (cds) Springer, Heidelberg.

Saxena, P. R., van Houwelingen, P. and Bonta, I. L. (1971) The effect of mianserin hydrochloride on the vascular responses to 5-hydroxytryptamine and related substances. Eur. J. Pharmac. 13: 295-305.

Saxena, P. R., Mylecharane, E. J. and Heiligers, J. (1985) Analysis of the heart rate effects of

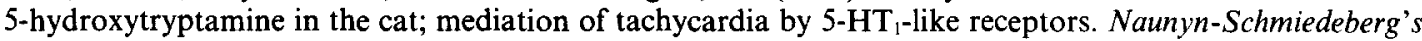
Arch. Pharmac. 330: 121-129.

Saxena, P. R., Duncker, D. J., Bom, A. H., Heiligers, J. and Verdouw, P. D. (1986) Effects of MDL 72222 and methiothepin on carotid vascular responses to 5-hydroxytryptamine in the pig: evidence for the presence of "5-hydroxytryptamine ${ }_{1}$-like" receptors. Naunyn-Schmiedeberg's Arch. Pharmac. 333: 198-204.

Saxena, P. R., Bom, A. H. and Verdouw, P. D. (1989) Characterisation of 5-hydroxytryptamine receptors in the cranial vasculature. Cephalalgia 9(Suppl. 9): 15-22.

Saxena, P. R., Villalón, C. M., Dhasmana, K. M. and Verdouw, P. D. (1992) 5-Hydroxytryptamine-induced increase in left ventricular $d P / d t_{\max }$ does not suggest the presence of ventricular $5-\mathrm{HT}_{4}$ receptors in the pig. Naunyn-Schmiedeberg's Arch. Pharmac. 346: 629-636.

Saxena, P. R., Bax, W. A. and Ferrari, M. D. (1993) 5-Hydroxytryptamine receptor subtypes and antimigraine action. Int. J. Pharmac. 25: 60-67.

Schoeffter, P. and Hoyer, D. (1990) 5-Hydroxytryptamine (5-HT)-induced endothelium-dependent relaxation of pig coronary arteries is mediated via $5-\mathrm{HT}$ receptors similar to the 5-HT $1 \mathrm{D}$ receptor subtype. J. Pharmac. exp. Ther. 252: 387-395. 
Schoeffter, P. and Sahin-Erdemli, I. (1992) Further characterization of the 5-hydroxytryptamine 5-HT-like receptor mediating contraction of guinea-pig iliac artery. Eur. J. Pharmac. 219: 295-301.

Schoemaker, R. G., Du, X. Y., Bax, W. A. and Saxena, P. R. (1992) 5-Hydroxytryptamine increases contractile force in porcine right atrium but not left ventricle. Naunyn-Schmiedeberg's Arch. Pharmac. 346: 486-489.

Schoemaker, R. G., Du, X. Y., Bax, W. A. and Saxena, P. R. (1993) 5-Hydroxytryptamine stimulates human isolated atrium but not ventricle. Eur. J. Pharmac. 230: 103-105.

Shen, Y., Monsma, F. J., Jr, Metcalf, M. A., Jose, P. A., Hamblin, M. W. and Sibley, D. R. (1993) Molecular cloning and expression of a 5-hydroxytryptamine, serotonin receptor subtype. J. biol. Chem. 268: $18200-18204$.

Shepheard, S. L., Williamson, D. J., Hill, R. G. and Hargreaves, R. J. (1993) The non-peptide neurokinin receptor antagonist, RP 67580 , blocks neurogenic plasma extravasation in the dura mater of rats. $B r . J$. Pharmac. 108: 1112.

Shepheard, S. L., Williamson, D. J., Cook, D., Baker, R., Street, L., Matassa, V. G., Beer, M., Middlemiss, D. N., Iversen, L., Hill, R. and Hargrieves, R. J. (1994) Functional pharmacology of a novel anti-migraine 5-HT $\mathrm{T}_{1 \mathrm{D}}$ receptor agonist MK-462 in vitro. In: Abstracts Book, Third IUPHAR Satellite Symposium on Serotonin, Chicago, p. 140.

Skingle, M., Scopes, D. I. C., Feniuk, W., Connor, H. E., Carter, M. C., Clitherow, J. W. and Tyers, M. B. (1993) GR127935: a potent orally active 5-HT 10 receptor antagonist. Br. J. Pharmac. 110: 9P.

Smith, D. W., Yocca, F. D., Yevich, J. P. and Mattson, R. J. (1992) Antimigraine alkoxypyrimidine derivatives. Bristol-Myers Squibb Co. Patent No. EP-464558.

Stacher, G., Abatzi Wcnzcl, T. A., Wiesnagrotzki, S., Bergmann, H., Schncider, C. and Gaupmann, G. (1993) Gastric emptying, body weight and symptoms in primary anorexia nervosa. Long-term effects of cisapride. Br. J. Psychiat. 162: 398-402.

Sumner, M. J. and Humphrey, P. P. A. (1989) $5-\mathrm{HTT}_{10}$ binding sites in porcine brain can be subdivided by GR43175. Br. J. Pharmac. 98: 29-31.

Sumner, M. J. and Humphrey, P. P. A. (1990) Sumatriptan (GR43175) inhibits cyclic AMP accumulation in dog isolated saphenous vein. Br. J. Pharmac. 99: 219-220.

Sumner, M. J., Feniuk, W., McCormick, J. D. and Humphrey, P. P. A. (1992) Studies on the mechanisms of 5-HT $\mathrm{H}_{1}$ receptor-induced smooth muscle contraction in dog saphenous vein. Br. J. Pharmac. 105: 603-608.

Sumner, M. K. (1991) Characterisation of the 5-HT receptor mediating endothelium-dependent relaxation in porcine vena cava. Br. J. Pharmac. 102: 938-942.

Tadipatri, S., van Heuven-Nolsen, D., Feniuk, W. and Saxena, P. R. (1991) Analysis of the 5-HT receptors mediating contractions in the rabbit isolated renal artery. Br. J. Pharmac. 104: 887-894.

Tadipatri, S., Feniuk, W. and Saxena, P. R. (1992) Rabbit isolated renal artery contractions by some tryptamine

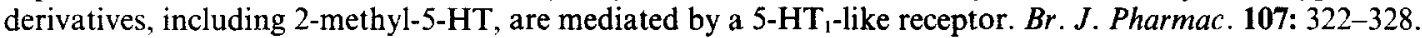

Talley, N. J. (1992) 5-Hydroxytryptamine agonists and antagonists in the modulation of gastrointestinal motility and sensation: clinical implications. Aliment. Pharmac. Ther. 6: 273-289.

Talley, N. J., Philips, S. F., Haddad, A., Miller, L. J., Twomey, C., Zinsmeister, A. R., MacCarty, R. L. and Ciociola, A. (1990) GR 38032F (ondansetron) a selective 5-HT, receptor antagonist, slows colonic transit in healthy man. Dig. Dis. Sci. 35: 477-480.

Tam, F. S.-F., Hiller, K. and Bunce, K. (1992) Investigation of the 5-HT receptor type involved in inhibition of spontaneous activity of human colonic circular muscle. Br. J. Pharmac. 106: 25P.

Tfelt-Hansen, P. and Pedersen, H. R. (1992) Migraine prophylaxis with 5-HT 2 partial agonists and receptor antagonists. In: 5-Hydroxytryptamine Mechanisms in Primary Headaches, pp. 305-310, Olesen, J. and Saxena, P. R. (eds) Raven, New York.

Tfelt-Hansen, P. and Saxena, P. R. (1993) Antiserotonin drugs. In: The Headache, pp. 373-382, Olesen, J., Tfelt-Hansen, P. and Welch, K. M. A. (eds) Raven, New York.

Tonini, M., Galligan, J. J. and North, R. A. (1989) Effects of cisapride on cholinergic neurotransmission and propulsive motility in the guinea-pig ileum. Gastroenterology 96: 1257-1264.

Trevethick, M. A., Feniuk, W. and Humphrey, P. P. A. (1986) 5-Carboxamidotryptamine: a potent agonist mediating relaxation and elevation of cyclic AMP in the isolated neonatal porcine vena cava. Life Sci. 38: 1521-1528.

Tricklebank, M. D. (1985) The behavioral response to 5-HT receptor agonists and the subtypes of the central 5-HT receptors. Trends Pharmac. Sci. 6: 403-407.

Tuladhar, B. R., Costall, B. and Naylor, R. J. (1991) Putative 5-HT 4 receptor involvement in the relaxations induced by 5-HT in the rat ileum. Br. J. Pharmac. 104: 151P.

Tuladhar, B. R., Costall, B. and Naylor, R. J. (1992) Variation in the relaxation response to 5-HT in different regions of the rat small intestine. Br. J. Pharmac. 105: 278P.

van Charldorp, K. J., Tulp, M. T. M., Hendriksen, B., Mons, H., Couwenberg, P. and Wouters, W. (1990) 5-HT-receptors in porcine basilar arteries closely resemble 5-HT ${ }_{(\mathrm{ID})}$-binding sites. Eur. J. Pharmac. 183: 1106-1107.

van Heuven-Nolsen, D., Tysee Klasen, T. H., Luo, Q. and Saxena, P. R. (1990) 5-HT,-like receptors mediate contractions of the rabbit saphenous vein. Eur. J. Pharmac. 191: 375-382.

Verdouw, P. D., Jennewein, H. M., Heiligers, J. P. C., Duncker, D. J. and Saxena, P. R. (1984) Redistribution of carotid artery blood flow by 5-hydroxytryptamine: effect of the 5- $\mathrm{HT}_{2}$ receptor antagonists ketanserin and WAL 1307. Eur. J. Pharmac. 102: 499-509. 
Villalón, C. M., Den Boer, M. O., Heiligers, J. P. C. and Saxena, P. R. (1990) Mediation of 5-hydroxytryptamine-induced tachycardia in the pig by the putative 5- $\mathrm{HT}_{4}$ receptor. Br. J. Pharmac. 100: 665-667.

Villalón, C. M., Den Boer, M. O., Heiligers, J. P. C. and Saxena, P. R. (1991) Further characterisation, by use of tryptamine and benzamine derivatives, of the putative 5-HT $\mathrm{H}_{4}$ receptor mediating tachycardia in the pig. Br. J. Pharmac. 102: 107-112.

Voigt, M. M., Laurie, D. J., Seeburg, P. H. and Bach, A. (1991) Molecular cloning and characterisation of a rat brain cDNA encoding a 5-hydroxytryptamine ${ }_{\mathrm{iB}}$ receptor. $E M B O \mathrm{~J}$. 10: 4017-4023.

Waeher, C., Hoyer, D. and Palacios, J. M. (1989) 5- $\mathrm{HT}_{3}$ receptors in the human brain: autoradiographic visualisation. Neuroscience 31: 393-400.

Waikar, M. V., Ford, A. P. and Clarke, D. E. (1994) Evidence for an inhibitory 5-HT 4 receptor in urinary bladder of rhesus and Cynomolgus monkey. Br. J. Pharmac. 111: 213-218.

Wardle, K. A. and Sanger, G. J. (1993) The guinea-pig distal colon-a sensitive preparation for the investigation of 5-HT 4 receptor-mediated contractions. Br. J. Pharmac. 110: 1593-1599.

Wardle, K. A., Ellis, E. S., Gaster, L. M., King, F. D. and Sanger, G. J. (1993) SB 20470: a highly potent and selective 5-HT ${ }_{4}$ receptor antagonist. Br. J. Pharmac. 110: 15P.

Watts, A. D., Feniuk, W. and Humphrey, P. P. A. (1981) A pre-junctional action of 5-hydroxytryptamine and methysergide on noradrenergic nerves in dog isolated saphenous vein. J. Pharm. Pharmac. 33: 515-520.

Weinshank, R. L., Zgombick, J. M., Macchi, M. J., Branchek, T. A. and Hartig, P. R. (1992) Human serotonin $1 \mathrm{D}$ receptor is encoded by a subfamily of two distinct genes: $5-\mathrm{HT}_{1 x}$ and 5-HT ${ }_{1 \mathrm{D} \beta}$. Proc. natn. Acad. Sci. U.S.A. 89: $3630-3534$.

Welch, K. M. A. (1993) Drug therapy of migraine. N. Engl. J. Med. 329: 1476-1483.

Wells, U., Ravenscroft, M., Bhandari, P. and Andrews, P. L. R. (1993) Serotonin and serotonergic drugs in emesis. In: Serotonin, Cell Biology to Pharmacology and Therapeutics, pp. 179-186, Vanhoutte, P. M., Saxena, P. R., Paoletti, R., Brunello, N. and Jackson, A. S. (eds) Kluwer, Dordrecht.

Westerberg, H. G. M. and Den Boer, J. A. (1989) Serotonin-influencing drugs in the treatment of panic disorders. Psychopathology 22(Suppl. 1): 68-77.

Winther, K. (1985) Ketanserin, a selection serotonin receptor antagonist, in relation to platelet aggregation and migraine attack rate. Cephalalgia 5(Suppl. 3): 402-403.

Woolley, D. W. and Shaw, E. (1953a) Some antimetabolites of serotonin and their possible application to the treatment of hypertension. J. Am. Chem. Soc. 74: 2948-2949.

Woolley, D. W. and Shaw, E. (1953b) An antiserotonin which is active when fed. J. Pharmac. exp. Ther. 108: 87.93 .

Yagaloff, K. A. and Hartig, P. R. (1985) [ $\left.{ }^{125}\right]$ Iodo-LSD binds to a novel 5-HT site on rat choroid plexus epithelial cells. J. Neurosci. 5: 3178-3183.

Yang, D. C., Goldstin, B., Moormann, A. E., Flynn, D. L. and Gullikson, G. W. (1993) SC-53606, a potent

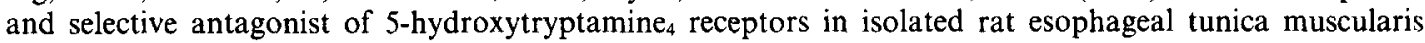
mucosae. J. Pharmac. exp. Ther. 266: 1339-1347. 